\title{
ATLAS FLORESTA AMERICANA. BONPLAND. 1850: LA IDENTIFICACIÓN DE LAS PLANTAS DE LA MATERIA MÉDICA MISIONERA DE PEDRO DE MONTENEGRO (SJ)
}

\author{
Atlas American Forest. Bonpland. 1850: Identification of plants from the "Materia Médica \\ Misionera" of Pedro de Montenegro (SJ)
}

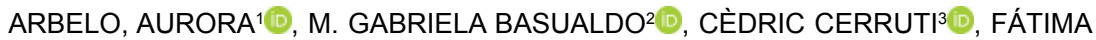

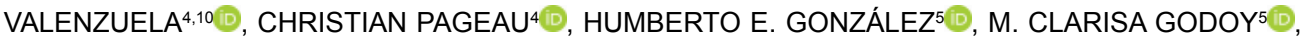 \\ MELINA RIABIS ${ }^{6}$, DAVID N. GUEVARA ${ }^{7}$, HÉCTOR A. KELLER ${ }^{8,10}$ \& PABLO C. STAMPELLA ${ }^{9,10}$
}

\begin{abstract}
Resumen: El manuscrito legado por Amado Bonpland, Atlas Floresta Americana 1850, obtenido de la Biblioteca de la Casa de la Cultura Benjamín Carrión (Quito, Ecuador) luego de gestiones realizadas por diversas entidades, nos permite contar con un material de gran valor históricocientífico y que aporta al estudio de la identificación de las plantas descriptas en la Materia Médica Misionera de Pedro de Montenegro. En tal sentido constituye un fondo documental que integra datos valiosos pertenecientes al período jesuítico, como también del período en que Bonpland permaneció en la cuenca rioplatense. El manuscrito fue analizado desde un enfoque interdisciplinario. Los objetivos del presente trabajo son: presentar el documento inédito, caracterizarlo históricamente, transcribirlo, traducirlo al español, actualizar los fitónimos al guaraní actual, actualizar las identificaciones de las plantas de la obra del jesuita Pedro de Montenegro, y comparar dichas identificaciones con otras realizadas sobre la misma obra. Se describen las características del manuscrito y el contexto histórico de su producción. Se presenta la afiliación botánica de las plantas identificadas por Bonpland a partir de la Materia Médica Misionera. Se resalta la importancia de este documento inédito como patrimonio, como también sus posibles aportes a los estudios jesuíticos, botánicos y farmacológicos en general.
\end{abstract}

Palabras clave: Botánica, documento inédito, ilustraciones, interdisciplinariedad, patrimonio.

\begin{abstract}
Summary: The manuscript bequeathed by Amado Bonpland, Atlas Floresta Americana 1850, obtained from the Library of the Casa de la Cultura Benjamín Carrión (Quito, Ecuador) after efforts made by various entities, allows us to have material of great historical-scientific value and that contributes to the study of the plants identification described in the Materia Medica Missionera of Pedro de Montenegro. In this sense, it constitutes a documentary collection that integrates valuable data pertaining to the Jesuit period, as well as the period in which Bonpland remained in the River Plate basin. The manuscript was analyzed with an interdisciplinary approach. The objectives of the present study are to present the unpublished document, characterize it
\end{abstract}

\footnotetext{
${ }^{1}$ Asociación Civil Cultural Bonpland. Delegada ICOM (Consejo Internacional de Museos) en Corrientes. Miembro de Comisión Directiva y Delegada ADiMRA (Asociación de Directores de Museos de la República Argentina) en Corrientes.

${ }^{2}$ Dirección de Relaciones Internacionales del Ministerio de Coordinación y Planificación de Corrientes.

${ }^{3}$ CRHIA, Universidad de La Rochelle, Francia.

${ }^{4}$ Núcleo de Estudios Históricos Coloniales, Instituto de Investigaciones Geohistóricas (CONICET-UNNE).

${ }^{5}$ Dirección de Idiomas de la Provincia de Corrientes.

${ }^{6}$ Archivo y Museo de Farmacobotánica (FFyB-UBA). Integrante de la Red de Museos UBA y miembro del comité de la Red de Archivos Históricos.

${ }^{7}$ Historiador e Investigador Numismático.

${ }^{8}$ Facultad de Ciencias Forestales (UNaM).

${ }^{9}$ Laboratorio de Etnobotánica y Botánica Aplicada (FCNyM, UNLP). Autor por correspondencia: pstampella@yahoo.com

${ }^{10}$ CONICET.
} 


\begin{abstract}
historically, transcribe it, translate it into Spanish, update the phytonyms to the current Guaraní, update the identifications of the plants of the Jesuit work Pedro de Montenegro, and compare these identifications with others made on the same work. The characteristics of the manuscript and the historical context of its production are described. The botanical affiliation of the plants identified by Bonpland from the Materia Medica Misionera is presented. The importance of this unpublished document as heritage is highlighted, as well as its possible contributions to Jesuit, botanical and pharmacological studies in general.
\end{abstract}

Key words: Botanic, heritage, ilustrations, interdisciplinarity, unpublished document.

\section{Introducción}

Siguiendo a Bonpland más allá de las fronteras

Poder relatar en la historia de la Dirección de Relaciones Internacionales de la Provincia de Corrientes que gestionó la obtención del manuscrito Atlas Floresta Americana (consultar información complementaria en línea) y poder compartirla con la comunidad científica y cultural, es sin duda motivo de celebración.

Este documento fechado en Montevideo (Uruguay) en el año 1850, se encuentra actualmente en la Biblioteca Nacional Eugenio Espejo de Quito (Ecuador). El mismo contiene 135 fojas con dibujos de plantas, sobre todo medicinales y otras plantas útiles. A todas se las designa con su nombre en latín, en lengua guaraní y en español.

Desde el momento en que pensamos, en el año 2008, el primer Proyecto de Cooperación: Puesta en valor de la vida, trabajo y producción de Amado Bonpland, realizado con la República de Francia, más precisamente con la Comunidad de La Rochelle (lugar de nacimiento del sabio Amado Bonpland), nos fijamos como uno de los objetivos de nuestra acción, el contar con este valioso material científico e histórico.

De este trabajo diplomático de más de 10 años, colaboraron el Ministerio de Relaciones Exteriores y Culto de la Argentina (Dirección General de Cooperación Internacional), la Embajada Argentina en Quito (Ecuador) y la Biblioteca Nacional Eugenio Espejo, y no podría haber sido de otra manera ya que seguramente el sabio francés nos quiso enseñar también en este punto las características que marcaron su vida, a saber: la perseverancia, la fortaleza y la claridad en las metas.

Explorador, médico, botánico, humanista, productor rural, político: todo esto contiene este ser admirable, por eso es tan merecido el tributo que realizaremos en este número de Bonplandia, revista científica correntina que cumple 60 años en la tarea de publicar artículos relacionados con la botánica.

En tiempos de pandemia, nos pareció interesante recordar la canción que Bonpland cantaba en su campo de Paso de los Libres (Corrientes): "Amigos, sigamos el camino divino. Amemos a nuestro prójimo, comenzando por nuestros vecinos" (Foucault, 1994).

\section{Bonpland en la cuenca rioplatense}

Aimé Jacques Alexandre Goujaud, llegó por segunda vez a América en el año 1817, donde realizó trabajos de investigación que implicarían 40 años de estancia, principalmente en Corrientes, pero también en Brasil, Paraguay y Uruguay.

Los estudios realizados en América por Humboldt y Bonpland fueron difundidos en Ecuador, en el año 2001, donde se concretó una exposición denominada El regreso de Humboldt (Holl, 2001), en el Museo de la ciudad de Quito, en cuyo catálogo se publicaron seis plantas mencionadas en el Atlas Floresta Americana presente en la Biblioteca Nacional del mismo lugar, las mismas son: "No22 en Atlas Floresta Americana, Guayaba campesina: gua: Arasa miri; $\mathrm{N}^{\circ} 32$ ceibo o chopo: Guarani zuinandy; $\mathrm{N}^{\mathrm{o}} 119$ Ninfea: Guarani Aguape guazú; No122 Camalea Vel achicoria de burro: g. caa vguaiguasupitaba; No126 Consuelda mayor americana: guani caa pita guazú, №131 Rais comestible: Guarani Mbacucú" (Díaz Piedrahita, 2001).

Desde el año 2002 la Subsecretaría de Cultura de Corrientes (hoy Instituto de Cultura) a través del Museo de Ciencias Naturales Amado Bonpland, se encuentra enriqueciendo el conocimiento interdisciplinar en torno a los aspectos del legado nacional 
e internacional para fomentar y fortalecer diferentes perspectivas contemporáneas a partir de la trama biográfica de Aimé Bonpland y Alexander von Humboldt.

El manuscrito Floresta Americana, fue nominado en Quito (Ecuador) en el año 2002, dentro del programa Memoria Científica de América Andina: las expediciones e investigaciones científicas en Bolivia, Colombia, Ecuador y Perú en los siglos XVIIIXIX; ante Memoria del Mundo (UNESCO), valiéndole certificado e inscripción en el Registro Nacional de la Memoria del Mundo con valor internacional para la cultura.

En el año 2008, sesquicentenario del fallecimiento del sabio francés, la Subsecretaría de Cultura, la Dirección de Relaciones Internacionales y el Museo Amado Bonpland de Corrientes, establecieron un Convenio de Cooperación entre el Museo de Historia Natural (La Rochelle, Francia) y el Museo de Ciencias Naturales Amado Bonpland (Corrientes, Argentina); siendo objetivos del mismo potenciar las actividades de ambas instituciones y fortalecer la figura de Amado Bonpland.

Por lo antes expuesto, nos interesó particularmente el manuscrito que se encontraba en Quito: Atlas Floresta Americana, Montevideo, 1850, cuya detección fue realizada por la arquitecta $\mathrm{P}$. Salas en el año 2009, en su visita a la Biblioteca Nacional del país antes mencionado. Es por esta razón que la Dirección de Relaciones Internacionales de la provincia de Corrientes inició, por vía diplomática, la solicitud de copia del citado Atlas con el fin de concretar un proyecto de publicación del manuscrito; la cual no fue posible dado que el documento fue retirado de consulta para su restauración.

Paralelamente, mientras se esperaba un resultado positivo en las gestiones diplomáticas, se presentó en el IV Encuentro Latinoamericano de Bibliotecarios, Archivistas y Museólogos (EBAM) en octubre del 2012, el proyecto Presencia de Caraí Arandú en Quito, a fin de continuar con acciones en torno al Atlas Floresta Americana (Arbelo, 2012).

Un antecedente de Floresta Americana se encuentra en la Revista Cultural de la Casa de la Cultura Ecuatoriana Benjamín
Carrión, donde se publicó un artículo denominado Libro del siglo XVIII. Bonpland descubrió la Floresta americana (Herrera Crespo, 2013). En éste se menciona que la Biblioteca Nacional Eugenio Espejo de la Casa de la Cultura Ecuatoriana posee un tesoro guardado, refiriéndose al Atlas Floresta Americana, entre más de 8.000 ejemplares de los siglos XV a XIX. Menciona además que en la administración de Raúl Pérez Torres (Ministro de Cultura y Patrimonio, designado por el presidente Lenín Moreno el 24 de mayo de 2017), se realizaron varias reuniones con los embajadores de Francia y Paraguay para viabilizar la publicación de este libro que finalmente no se concretó.

En el año 2017, bicentenario del viaje de Amado Bonpland por segunda vez a América, se creó en Corrientes, la Asociación Cultural Bonpland. Con el ánimo de funcionar como centro de referencia internacional sobre el estudio, investigación y difusión de la labor desarrollada por el científico francés, se propone la creación de un fondo documental vinculado a estos temas, conformando así una red de transferencia e intercambio local y extensivo a otros ámbitos.

En los últimos años se realizaron coloquios, foros Franco-Argentinos y congresos internacionales, con el fin de exponer críticamente los saberes entre Europa y América, a partir de las contribuciones de Amado Bonpland y Alexander von Humboldt en los espacios culturales de las regiones americanas en las cuales vivieron, trabajaron y ejercieron su influencia.

En el año 2019 el Dr. C. Cerruti -investigador francés y primer pasante del Museo Amado Bonpland en el año 2002- entrevista a la Directora de Biblioteca Pública de la Cultura Benjamín Carrión, S. Bolaños Muñoz. En ese momento, la misma asumió el compromiso de digitalización del Atlas Floresta Americana.

E1 3 de octubre de 2019, la Dra. M. G. Basualdo, Directora de Relaciones Internacionales (Corrientes), solicita al Sr. R. D. Giustozzi, embajador de Argentina en Quito, la copia del Atlas Floresta Americana, Bonpland, 1850; recibiendo una respuesta positiva y logrando obtener la digitalización de la obra citada. 
A partir de este logro se convoca a formar un equipo de trabajo conformado por especialistas y referentes en el tema, para estudio y difusión del manuscrito inédito donde el Instituto de Botánica del Nordeste (IBONE), Corrientes, se constituye en actor principal debido a que esta institución posee un importante fondo documental sobre Bonpland y ofrece la publicación en la revista Bonplandia.

\section{El Atlas Floresta Americana como Patrimonio} Documental y su relación con la Materia Médica Misionera de Pedro de Montenegro

El Atlas Floresta Americana posee valor documental histórico y científico, no sólo por corresponder a un manuscrito de Bonpland, sino porque constituye uno de los pocos intentos de identificación de las plantas descriptas en la Materia Médica Misionera de Pedro de Montenegro. El sabio francés estudió y coleccionó abundante material botánico $\mathrm{y}$, a pesar que el Dr. Juan Pujol le ofreció la imprenta de la Provincia de Corrientes para materializar publicaciones científicas propias o ajenas, con la misma calidad que podría concretarse en París, realizó escasas publicaciones en Argentina.

Las fuentes históricas jesuíticas han sido ampliamente utilizadas como corpus de información entrabajos botánicos,zoológicos, históricos, etnográficos, etnohistóricos y más recientemente etnobotánicos (Furlong, 1948; Métraux, 1948; Castex, 1968; Susnik, 19791980; Rosso, 2013; Stampella et al., 2013, 2019). Sin duda alguna, constituyen fuentes documentales ricas en información -muchas veces detallada- de diversos aspectos referidos a las etnias locales, plantas y rutas de introducción de las mismas, prácticas de manejo, relación con el entorno, estrategias de desarrollo rural, entre otras (Carbonell, 1992; Stampella et al., 2013, 2019; Keller et al., 2018).

Son variados los trabajos científicos que analizan diversos aspectos de la obra de Pedro de Montenegro, como la vida del autor y la influencia de la Materia Médica Misionera en la farmacología y la medicina (Martínez et al., 1990; Anagnostou, 2005). Otros trabajos se focalizan en la difusión, circulación y producción de conocimientos médicos y farmacológicos en los inicios del siglo XVIII (Deckmann Fleck et Poletto, 2012), su posicionamiento teórico en el tratamiento de las enfermedades, los saberes nativos y las resignificaciones en tal contexto (Poletto, 2014). Por último, cabe mencionar aquellos que estudian un recorte de algunas plantas usadas para enfermedades mentales (Ibarra, 2007) y para el tratamiento contra el veneno de ofidios (Ricciardi et al., 1996) o las plantas autóctonas componentes de las drogas encontradas en la botica jesuítica de la ciudad de Santa María de los Buenos Ayres (Perkins, 2007). Recientemente, Scarpa et Anconatani (2019), desde la etnobotánica histórica, han comenzado a sistematizar, cuantificar e interpretar las aplicaciones medicinales y de otro tipo que se le asignan a cada una de las plantas mencionadas en esta obra.

Las identificaciones de las plantas de obras jesuíticas suponen distintos grados de dificultad, dependiendo de los autores que se trate, de la claridad y extensión de sus descripciones, como también de la presencia o no de ilustraciones que las acompañen. Rosso et Scarpa (2012) identificaron más del 80\% de las plantas de la obra de Florian Paucke, la mayoría de ellas a nivel de especie. Sin embargo, para la obra de Pedro de Montenegro, son escasos los intentos de aventurarse en la identificación botánica de las plantas allí mencionadas. Poletto et Welter (2011) seleccionan cinco plantas de la obra, las identifican y discuten sus aplicaciones terapéuticas y la vinculación con las prácticas médicas del siglo XVIII. Algo similar ocurre con los trabajos de Ricciardi et al. (1996), Deckmann Fleck et Poletto (2012) y Stampella et al. (2013). El primero de ellos se focaliza en la identificación de las plantas empleadas como contravenenos ofídicos. Deckmann Fleck et Poletto (2012), al indagar acerca de la circulación de conocimientos y prácticas científicas, basadas en concepciones hipocrático-galénicas, identifican algunas plantas que mencionan en el relato. El último, analizando varias fuentes documentales -entre ellas las jesuíticas- describe la introducción, establecimiento y apropiación de los frutales euroasiáticos.

Desde la etnobotánica histórica, el trabajo de Stampella et al. (2018), releva los espacios 
de manejo de las plantas en el entorno de las misiones jesuíticas, las prácticas de manejo llevadas a cabo en los mismos, y los etnotaxa involucrados, empleando diversas fuentes documentales jesuíticas. En ese mismo trabajo se identificaron taxonómicamente 25 plantas de la Materia Médica Misionera, mediante el empleo de bibliografía de esa zona geográfica y diversos trabajos específicos de familias y géneros botánicos. Sin embargo, queda mucho por aportar en lo que respecta a la identificación de las plantas de la obra mencionada.

Finalmente, cabe mencionar que el manuscrito referido fue mencionado por Díaz Piedrahita (2001: 77) de esta manera: "La Biblioteca Nacional del Ecuador, en Quito, posee un libro legado por él (refiriéndose a Bonpland), que contiene 135 dibujos de plantas, sobre todo medicinales y otras plantas útiles. A todas se les designa con su nombre en latín y en lengua guaraní. Por lo menos el índice y las descripciones proceden de la pluma de Bonpland. Se presume que los dibujos fueron elaborados por un nativo de la tribu de los guaraníes". Sin embargo, no se realizó un análisis del mismo.

Es aquí donde nos posicionamos, en la vacancia de la identificación de las plantas de la obra de Montenegro, aspecto sin el cual toda la información referida a las plantas mencionadas en la misma queda exenta de valor científico. El manuscrito Atlas Floresta Americana, viene a llenar un vacío al respecto.

Los objetivos del presente trabajo interdisciplinario son: a) presentar a la comunidad científica el manuscrito inédito de Bonpland, b) caracterizarlo desde el punto de vista histórico, c) transcribirlo, d) traducir las anotaciones del francés al español, e) actualizar los fitónimos al guaraní actual, f) actualizar las identificaciones de las plantas de la obra del jesuita Pedro de Montenegro, y g) comparar dichas identificaciones con otras realizadas sobre la misma obra.

\section{Materiales y Métodos}

El manuscrito fue abordado desde una perspectiva interdisciplinaria. La transcripción implicó una serie de etapas y momentos que nos interesaría explicarlos con profundidad. El primer paso implicó la lectura del manuscrito y el reconocimiento de la caligrafía utilizada a lo largo del documento. Una vez alcanzado el primer contacto con la fuente, se procedió a la transcripción de la documentación que, mayoritariamente, se encontraba en varias lenguas. Para garantizar una fiel reproducción de la fuente, y frente a la dificultad de identificar algunas letras, se procedió a una confrontación constante y permanente con los nombres científicos de las distintas plantas que se presentaban en el documento. En un segundo momento, se emprendió la traducción al castellano de las apreciaciones o explicaciones en latín, en ese aspecto, se tuvo en cuenta un proceso de correcciones, actualización gramatical u ortográfica del francés. En un tercer momento, la transcripción fue revisada por expertos en botánica para un análisis documental más riguroso. En el mundo de la edición y transcripción de fuentes históricas, existe gran diversidad de modos o formas de transcripciones documentales, en esta edición, se procedió a una literal o fiel al manuscrito (Tanodi Branka, 2000). Es decir, ofrecemos al lector un documento fiel o una "copia a la letra" en su aspecto paleográfico e incorporamos una traducción al castellano.

Para analizar el contexto en el cual se produjo el manuscrito, se analizó el intercambio epistolar de A. Bonpland presente en el fondo documental del Archivo del Museo de Farmacobotánica Juan Aníbal Domínguez (Facultad de Farmacia y Bioquímica de la Universidad de Buenos Aires).

La traducción y actualización de las palabras presentes en el manuscrito a la lengua guaraní se basan en los cambios que se produjeron en la codificación de la lengua a raíz del Congreso de la Lengua Guaraní llevado a cabo en Montevideo (Uruguay) en el año 1950. En esta convención se conformó el alfabeto moderno conocido como ACHEGETY, ya que históricamente la lengua guaraní se transmitía de generación en generación de manera oral. Se utilizó como fuente el trabajo exhaustivo de Berro García (1950).

La actualización de la nomenclatura botánica presentada por Bonpland se realizó 
en base al catálogo The Plant List (2013). Para cada planta se transcriben los nombres de las láminas -tanto españoles, guaraníes, y tupíes-, se agrega la traducción de las anotaciones de Bonpland (si las hubiere) y la identificación del manuscrito. A continuación se provee una identificación botánica actual de acuerdo a la metodología explicitada (nombres/s científico/s y familia botánica, si los hubiere).

\section{Resultados y Discusión}

\section{Descripción y caracterización del manuscrito}

El Atlas de Floresta Americana es un manuscrito compuesto por 135 láminas $\mathrm{y}$ un índice de dibujos que se compone de 12 fojas (Fig. 1). Este manuscrito está fechado en Montevideo, 5 de octubre de 1850 y se le atribuye al botánico y naturalista Aimé Bonpland. Cabe destacar que Aimé Bonpland viajaba cada año a cobrar su pensión vitalicia a Montevideo, informándose allí de las novedades científicas. Que el documento haya sido fechado en dicha ciudad, refleja que pudo haber sido concluido en algunas de sus estancias (Furlong, 1969). Si cotejamos la caligrafía del manuscrito con otras fuentes escritas por el mismo botánico, por ejemplo aquellas presentadas por Giberti (2008), encontramos enorme similitud.

El documento, en la actualidad, se conserva en la Biblioteca Nacional Eugenio Espejo (Ecuador) y se encuentra en la colección Fondo Jesuita, correspondiente a la signatura FJ08953 (Fig. 2).

En la trama intertextual, podemos señalar que el manuscrito apela a varias lenguas para referir a las plantas y a sus referencias en el índice final. En la primera parte, las láminas están en castellano, tupí y guaraní, lo que refleja el dominio lingüístico misioneroparaguayo alcanzado en poco más de tres décadas de permanencia en el Paraguay, Misiones y Corrientes. Si bien las lenguas tupí y guaraní constituyen en realidad una misma lengua, durante el siglo XVI, el etnónimo tupí fue acuñado por los españoles para referirse a los indígenas de las costas del Brasil portugués, mientras que el etnónimo guaraní se refería a la lengua hablada en los amplios territorios explorados por los españoles entre la isla de Santa Catarina y los contrafuertes de los Andes, pasando por Asunción (Candela et Melià, 2015). Entre el siglo XVI y el siglo XIX, fueron cambiando las percepciones de la realidad étnica, cultural y lingüística del tupí-guaraní. En el momento que se escribe esta fuente, la mayoría de los escritos empiezan a aplicar el calificativo general de guaraní, con lo cual, el documento producido por A. Bonpland representa un caso rarísimo en términos lingüísticos por la diferenciación en tupí y guaraní (ver por ejemplo Melià, 1992, 2003).

En la segunda parte, el índice de dibujos apela al latín y al francés. El latín está presente para nombrar científicamente a las plantas como compendio botánico, mientras que el francés se utiliza en las descripciones que constituyen su diario de campo. El estilo de la caligrafía manifiesta un trazo apresurado y desprolijo propio de su registro cotidiano, escrito a partir de sus recuerdos o memorias.

Este manuscrito se encuentra en un buen estado de conservación, y desde luego, está escrito a mano. Se observa que el nombre del documento fue incorporado luego, pues no es compatible la caligrafía del título con el resto del manuscrito. Con lo cual, desconocemos si este documento tenía otro encabezado o se encontraba anexo a alguna carta producida por Aimé Bonpland. La primera lámina tiene una rúbrica inicial en el margen superior del documento; a su vez, todas las láminas aparecen enumeradas desde la número 1 a la 135.

En la Biblioteca Nacional de nuestro país, en sección reservada, número 94 , se encuentra un volumen encuadernado en pergamino, con 460 páginas en papel de algodón. El mismo no pertenece a Montenegro, sino que se trata de una copia posterior. Los 136 dibujos de plantas que posee no son en su mayoría originales y están tomados de la obra de W. Piso, especialmente de la comentada por Bonti, De Indiae Utriusque Re Naturali Et Medica, consultada por Montenegro quien trasladó algunas plantas que les resultaron interesantes. El nombre de Materia Médica 


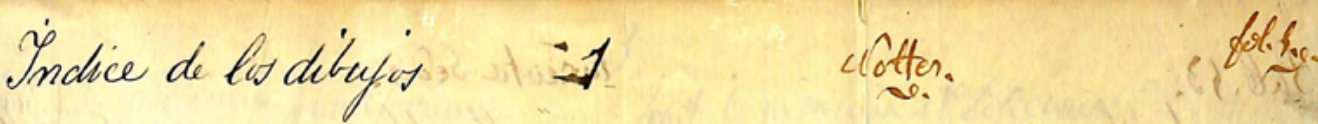

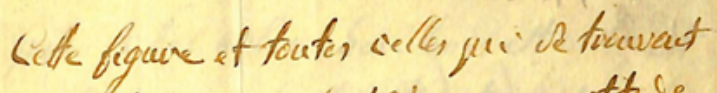
Daus cet onsirage sout ilune ineracthide isuarquable.

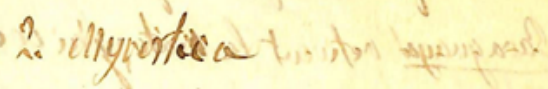

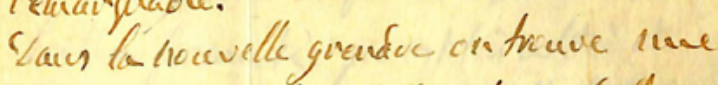

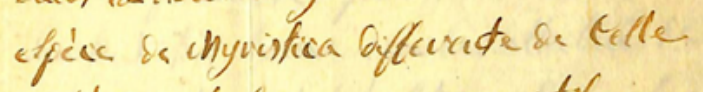

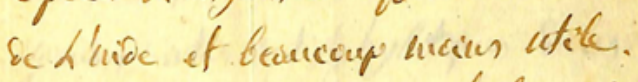

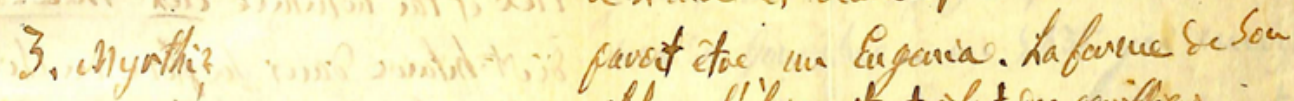
zalu.

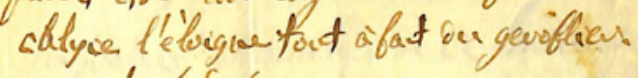
incertas bevis. 4. Sepercuntia. 4 id. id? 2. $\therefore$.

8. Gancur (ancla ot

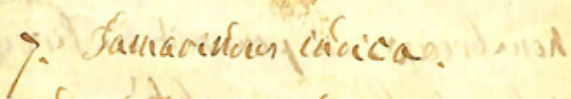

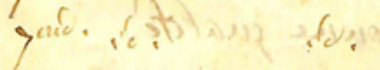

8. Guayacum Sanctum.

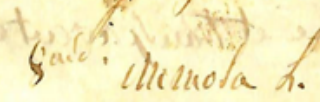

9. Copaifera invica. So.

incrita Seris

19. Pordoia

$\{2$.

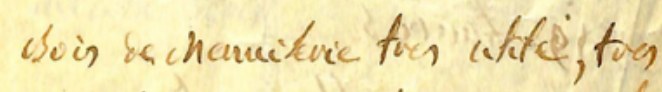

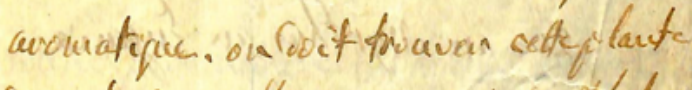
becute baun fouveagen of in ine thetaive Sour knom de havers.

2. - - - ancentor Sévis.

Fig. 1. Primera foja del índice de las láminas del manuscrito donde Bonpland identifica a las especies vegetales y realiza anotaciones referidas a las mismas.

Fig. 1. First index page of the plates of the manuscript where Bonpland identifies the plant species and makes notes referring to them. 


\begin{tabular}{|c|c|c|}
\hline \multicolumn{3}{|c|}{ FICHA TÉCNICA } \\
\hline TÍTULO & Atlas Floresta Americana & \\
\hline TIPO & Manuscrito & \\
\hline AUTOR & Índice y anotaciones Amado Bonpland & \\
\hline FECHADO & Montevideo & \\
\hline UBICACIÓN ACTUAL & $\begin{array}{l}\text { Biblioteca Pública Casa de la Cultura } \\
\text { Ecuador }\end{array}$ & \\
\hline PAÍS & Ecuador & \\
\hline CIUDAD & Quito & \\
\hline AÑO & 1850 & \\
\hline COLECCIÓN & Fondo Jesuita & Tapa. P. Herrera Crespo \\
\hline SIGNATURA & FJ08953 & \\
\hline CUBIERTA EXTERNA & Posib. Encuad. en media pasta & \\
\hline CARACTERÍSTICAS & Tinta y lápiz sobre papel & \\
\hline PÁGINAS & 135 & \\
\hline MEDIDAS & $28 \times 12 \mathrm{CM}$ & \\
\hline SITUACIÓN & $\begin{array}{l}\text { No para préstamo (Acceso } \\
\text { Restringido) }\end{array}$ & \\
\hline ESTADO DE CONSERVACIÓN & Bueno & Hojas internas. P. Salas \\
\hline
\end{tabular}

Fig. 2. Ficha Técnica del Atlas Floresta Americana. Bonpland. 1850.

Fig. 2. American Forest Atlas Technical Sheet. Bonpland. 1850.

Misionera, fue dado posteriormente por Manuel Ricardo Trelles (Montenegro, 1945).

En el Atlas considerado, luego de las ilustraciones hay seis folios, escritos de ambas carillas, con anotaciones en francés de A. Bonpland. En las mismas se puede apreciar el número de ilustración, la identificación (si fue lograda, a veces a nivel de especie, género o familia), y diversas anotaciones referidas a aspectos morfológicos, utilitarios, ecológicos, similitudes con otras plantas, comparaciones y referencias a la obra de Auguste de Saint-Hilaire, Carl Ludwig Willdenow y Christiaan Hendrik Persoon.

\section{El contexto de escritura del manuscrito}

En 1850, Aimé Bonpland viajó a Montevideo dentro de un contexto muy particular. La ciudad antirrosista, sostenida por las fuerzas navales francesas, era entonces sitiada por las fuerzas rosistas del general Oribe desde 1843. Ese Sitio Grande (1843-1851) era un episodio de la Guerra Grande (1839-1852) dentro del cual A. Bonpland, como muchos franceses, participó. Su actuación había empezado desde 1839 como médico al lado de las fuerzas correntinas antirrosistas del gobernador correntino Genaro Berón de Astrada. Después de la muerte de ese gobernador durante la batalla de Pago Largo, Bonpland siguió como plenipotenciario de Pedro Ferré, amigo suyo y nuevo gobernador de Corrientes, ante el gobierno del general uruguayo antirrosista Fructuoso Rivera. Con dicho título y varias misiones diplomáticas llevadas a cabo entre 1840 y 1842, Bonpland conoció Montevideo y a la comunidad científica y francesa que albergaba.

Las derrotas de las fuerzas antirrosistas a partir de 1842 -pues la situación política era inestable en esa región del mundo- obligaron a Bonpland a retirarse por varios años a su chacra brasileña de São Borja. Esa situación, sumada a la no presentación del certificado 
de supervivencia debido a la privación de su libertad, le impidió cobrar una pensión otorgada en 1805 por el gobierno francés en compensación de su donación a su país de un herbario colectado durante la expedición americana en compañía de Alexander von Humboldt. Dicha pensión formaba una base económica primordial para sostener las empresas agrícolas que el francés quería llevar a cabo, pero era sometida al envío anual de un certificado de vida que solamente podía estar atestado por las autoridades consulares francesas.

Si bien Bonpland mantuvo contactos y pudo viajar dentro de la provincia de Corrientes, era demasiado peligroso viajar hasta Buenos Aires donde gobernaba Juan Manuel de Rosas. En 1849, el francés tuvo la oportunidad de viajar hasta Porto Alegre por motivos principalmente comerciales $\mathrm{y}$, desde aquella ciudad, ir nuevamente hacia Montevideo para ponerse en contacto con las autoridades francesas a fin de obtener el famoso certificado de vida. Residió en la capital uruguaya desde final de agosto hasta principios de octubre de 1849. Allí volvió a frecuentar a las personas que había conocido entre 1840 y 1842 . Conoció también a la comunidad francesa montevideana, erudita y política, que vivía el Sitio Grande antes de volver a São Borja por el mismo camino marítimo después terrestre pasando por Porto Alegre, cruzando el estado de Rio Grande do Sul por vía terrestre para volver a São Borja en diciembre de 1849.

El 21 de mayo de 1850, A. Bonpland emprendió otro viaje hacia Montevideo con la misma meta económica, acompañado, circunstancialmente, del daguerrotipista norteamericano Fredricks, y sus socios, el francés Penabert y el argentino Masoni (BCMNHN Francia, MS 209: 29), pero esa vez no por la ruta de Porto Alegre sino bajando el río Uruguay. El francés obtuvo, al parecer, la protección política de los rosistas que gobernaban entonces la mesopotamia argentina. En Corrientes Bonpland se había acercado al gobernador federal, rosista y reformista Benjamín Virasoró. La política y las alianzas complejas de ese momento de la historia argentina resultaron beneficiosas al francés quién pudo obtener el auxilio de unos dirigentes rosistas para irse hasta una ciudad antirrosista. El 13 y 14 de julio fue recibido por el gobernador rosista de Entre Ríos y estrecho aliado de Benjamín Virasoró, el general Justo José de Urquiza, en su estancia de Concepción del Uruguay.

Sería temeroso opinar sin ninguna documentación que Bonpland, a semejanzas de principios de la década 1840 , hubiese podido llevar a cabo alguna misión diplomática. $\mathrm{Su}$ posición neutral como científica le ayudó probablemente en conseguir tan improbable éxito. Durante su viaje, registró rocas, minerales y fósiles, en su Catálogo Geológico 1858 (BCMNHN Francia, MS 210: 54-58), en particular las relacionadas con el Salto Grande y Salto Chico, entre Federación y Concordia, Entre Ríos. A principios de agosto de 1850, Bonpland llegaba a Montevideo donde iba a residir más de tres meses. Esta ciudad veía entonces su población aumentada por refugiados argentinos, vascos españoles y franceses. Después del 27 de agosto y de la convención Le Prédour-Arana firmada entre Rosas y Francia, el gobierno de la ciudad dejó de ser sostenido por las fuerzas navales francesas.

Sabemos que Bonpland frecuentó la comunidad política, científica y económica de la ciudad, pero aún quedan por descubrir los detalles de su estadía y de los vínculos que pudo establecer. Entre dichos detalles, dando continuidad al mencionado catálogo geológico, registró rocas y fósiles del Cerro de Montevideo, y en su "Journal de Botanique" (TIBF Bs. As., 42: 13-14), registró la diagnosis y notas de las plantas que recogió; y apareció el Atlas Floresta Americana.

En octubre de 1850, fecha de datación del manuscrito, Bonpland hizo comentarios sobre un trabajo con 135 especies de plantas descriptas, facilitado por el Dr. B. Odicini, en un estudio jesuita ilustrado. Él no identificó al autor, pero no quedó conforme con la calidad de las ilustraciones, comentando, todas las figuras de esta obra son de una remarcable inexactitud (Bell, 2010). Con respecto al estudio ilustrado jesuítico, posiblemente se refiera al amigo 
personal de A. Bonpland, Jean Pierre Gay (1815-1891), padre jesuita de origen francés, con quien mantenía una profunda amistad. Fue portador de su biblioteca y custodio de sus colecciones.

En el Archivo Bonpland del Museo Juan Aníbal Domínguez de Buenos Aires, se conserva un borrador trunco de tres fojas, de autoría Bonpland, fechado el 5 de octubre de 1850 , escrito en francés, donde se menciona a Humboldt y a un catálogo (AMFBJAD Bs. As., Caja 2).

Se puede comprobar en el índice del Atlas que Bonpland constató y escribió que la ilustración del Ilex que contenía no correspondía a ninguna de las especies de Ilex existentes que él estimaba a tres o cuatro. Es decir que Bonpland se encontró con una nueva especie de Ilex que él nunca había visto durante sus investigaciones. Es otro aspecto que muestra que Bonpland descubrió una obra original en la cual no participó. El dibujante del Atlas no puede ser Bonpland ya que el botánico no era buen dibujante y que, en una nota sobre el Atlas, puso de relieve la calidad de las ilustraciones, comentario que corresponde a un lector antes que a un autor.

Durante el año de 1850, se relevaron 49 correspondencias recibidas por A. Bonpland, y seis cartas enviadas durante el segundo semestre a A.V. Porto, Francois Delssert, a la casa comercial Desmarest y Ducoing, Chevalier Gravelle, Sagastume y a otra persona no identificada (AMFBJAD Bs. As., Cajas 6, 7, 9, 11, 15).

Esta presencia física del sabio francés en Montevideo en 1850, donde visitaba a Martín de Moussy y al Dr. Brunel, coincide con el Viaje de San Borja a Montevideo, por el Uruguay, donde colectó especies vegetales desde el No 2489 al 2495 en Mayo-Junio de 1850 (Bonpland, 1924: 11-12). En OctubreNoviembre de 1850 colecta en Montevideo desde el No 2495 al 2502 (Bonpland, 1924: 13-14). Luego en Diciembre de 1850 viaja de Montevideo a San Borja describiendo en su diario de "Botanique" desde el No 2503 al 2514 (Bonpland, 1924: 15-17). Es interesante la descripción en sus manuscritos de especies vegetales que se encuentran en el Atlas Floresta Americana.

\section{Origen de la información del Atlas}

Buscando al prestador - $i \mathrm{y}$ propietario?del Atlas B. Odicini, se sabe que se radicó en Montevideo a partir del año 1844, donde desempeñó un papel activo como antirrosista pues era cirujano del Ejército uruguayo desde 1848, luego de la Legión italiana. Odicini fue miembro fundador de la Sociedad de Medicina de Montevideo, de la que A. Bonpland fue Miembro Honorario, dado que viajaba frecuentemente a Montevideo a enviar correspondencia y recibir elementos farmacéuticos. En este lugar se reunía con franceses en la trastienda de la Botica de Julio Lenoble y Domingo Parodi (Pou Ferrari et Mañe Garzón, 2012). No hay duda en que este médico frecuentaba en Montevideo a sus pares Brunel y Martin de Moussy, ambos futuros biógrafos de Bonpland, como recurría también a la comunidad masónica y erudita montevideana. Parece que Bonpland conoció a sus pares llegando a Montevideo. Acerca de su relación con Odicini, parece que el botánico francés y el cirujano sardo se conocieron y se frecuentaron únicamente durante la estadía de Bonpland en Montevideo, quizás más tarde durante los otros viajes de Bonpland hasta Montevideo en 1854 y 1855-1856 aunque las fuentes documentales no indican otro encuentro o vínculo en el estado de las investigaciones actuales.

Parece entonces que para encontrar la procedencia del Atlas Floresta Americana habría que profundizar las investigaciones en el entorno de la comunidad científica por ambos lados del Río de la Plata. Dámaso Antonio Larrañaga en Montevideo o Pedro de Angelis en Buenos Aires, podrían estar vinculados con el Atlas como fomentadores y pilares de las ciencias rioplatenses, también como coleccionistas y mediadores culturales. Si bien ambos intercambiaron con Bonpland, las últimas huellas de intercambio entre el francés y Larrañaga datan de 1818, mientras que de Angelis y Bonpland cesaron toda comunicación después de 1837 (Cerruti, 2012). Aunque es posible que la creación y la difusión del Atlas Floresta Americana, como muchos otros bienes culturales, sea ligada a Larrañaga o de Angelis, no parece que haya conexión directa con Bonpland 
sino con Odicini y su séquito dentro del cual la masonería era muy presente, por lo que habría que llevar a cabo investigaciones amplias.

Llama la atención el cambio de título con respecto a la obra Materia Médica Misionera del jesuita Pedro de Montenegro y se relaciona con una supuesta autoría del documento. En relación con el orden y la disposición de las láminas que comienzan con el Cacao, respondería la obra de Segismundo Asperger (Azara, 1865) que, si bien no se observan dibujos, comienza la página 1 con las virtudes del Cacao (Perkins, 2007). Las letras "A. D." que figuran en el canto del documento corresponderían al autor, propietario o editor del Atlas. Siguiendo la pista de los franceses que pasaron por Montevideo o se radicaron allí, podría corresponder a Alfred Demersay, quien consiguió explorar el Paraguay durante los años 1840; Adolphe D'Hastrel, reconocido pintor, acuarelista y litógrafo francés que en ese tiempo estaba en Montevideo. Se podría tratar también del médico francés Adolphe Déroseaux quien fue designado en 1849 como Conservador del Museo Nacional del Uruguay, como preparador de arte de historia natural y conservador (Le Patriote Francais, 1849). Amigo de Brunel y Martin de Moussy, formó parte de la Legión francesa y al desvincularse de ella integró como cirujano de segunda clase en el hospital de la Legión Italiana a cargo de Odicini (Le Patriote Francais, 1849).

Así se presentan unas pistas de investigación locales; quedan muchas otras por estudiar, más aún para entender de qué manera el Atlas fue trasladado hacia Quito. No teniendo ni lugar ni fecha de edición, podría ser una obra -incluso parte de una obra- realizada durante la época jesuítica, en base a la cual Bonpland realiza sus anotaciones. En fin, muchas pistas son posibles y cobran un periodo alrededor de un siglo y medio. Como complemento futuro, la interdisciplina vinculada a la conservación y restauración de especialistas en el área del papel y libro antiguo, serían de gran utilidad para la recopilación de información necesaria y el conocimiento de la obra, su materialidad y las circunstancias que determinan su valor $\mathrm{y}$ el alcance de los deterioros que sufre en la actualidad este Atlas. La descripción del manuscrito en su materialidad, y las alteraciones que derivan de su estado de conservación podrían arrojar datos de gran utilidad para la contextualización histórica de esta obra.

Finalmente, el conocimiento de las ciencias y el empleo frecuente del método científico, podrán integrar el contexto histórico y cultural que enmarca esta búsqueda, que podría potenciarse para influir en las incertidumbres y arrojar luz a las investigaciones.

\section{La afiliación botánica de las plantas presentadas en la obra}

En la Tabla 1 se estructuran diferentes aspectos relevados del manuscrito Atlas Floresta Americana. En este documento, Bonpland relevó 139 etnotaxa, de los cuales 21 fueron identificados a nivel de especie, 71 a nivel genérico, 23 a nivel familia y 24 no fueron identificados (incertae sedis e ignotum). Los etnotaxa se corresponden con 46 familias botánicas, de las cuales las más representadas fueron Asteraceae (16\%), Fabaceae (12\%), Lamiaceae (7\%), Myrtaceae (7\%) y Piperaceae (5\%). Cabe destacar que de los 15 etnotaxa pertenecientes a la familia Compositae (Asteraceae), sólo dos fueron identificados a nivel genérico (Baccharis y Solidago), detalle que se explica posiblemente por la compleja diversidad de esta familia de plantas, la más rica en taxa de Misiones (Zanotti et al., 2020), pero en la cual Bonpland poco incursionó taxonómicamente.

Cabe destacar que las láminas con imágenes que acompañan este manuscrito no son las mismas que acompañan las diversas versiones de la Materia Médica Misionera de P. Montenegro, aunque mantienen muchas similitudes y al parecer fueron copiadas de esta obra, basada a la vez, en parte, en la obra antes mencionada de W. Piso (Fig. 3). Con respecto a la autoría de estas láminas, Díaz Piedrahita (2001: 77) menciona que pudieron haber sido realizadas por algún guaraní. 


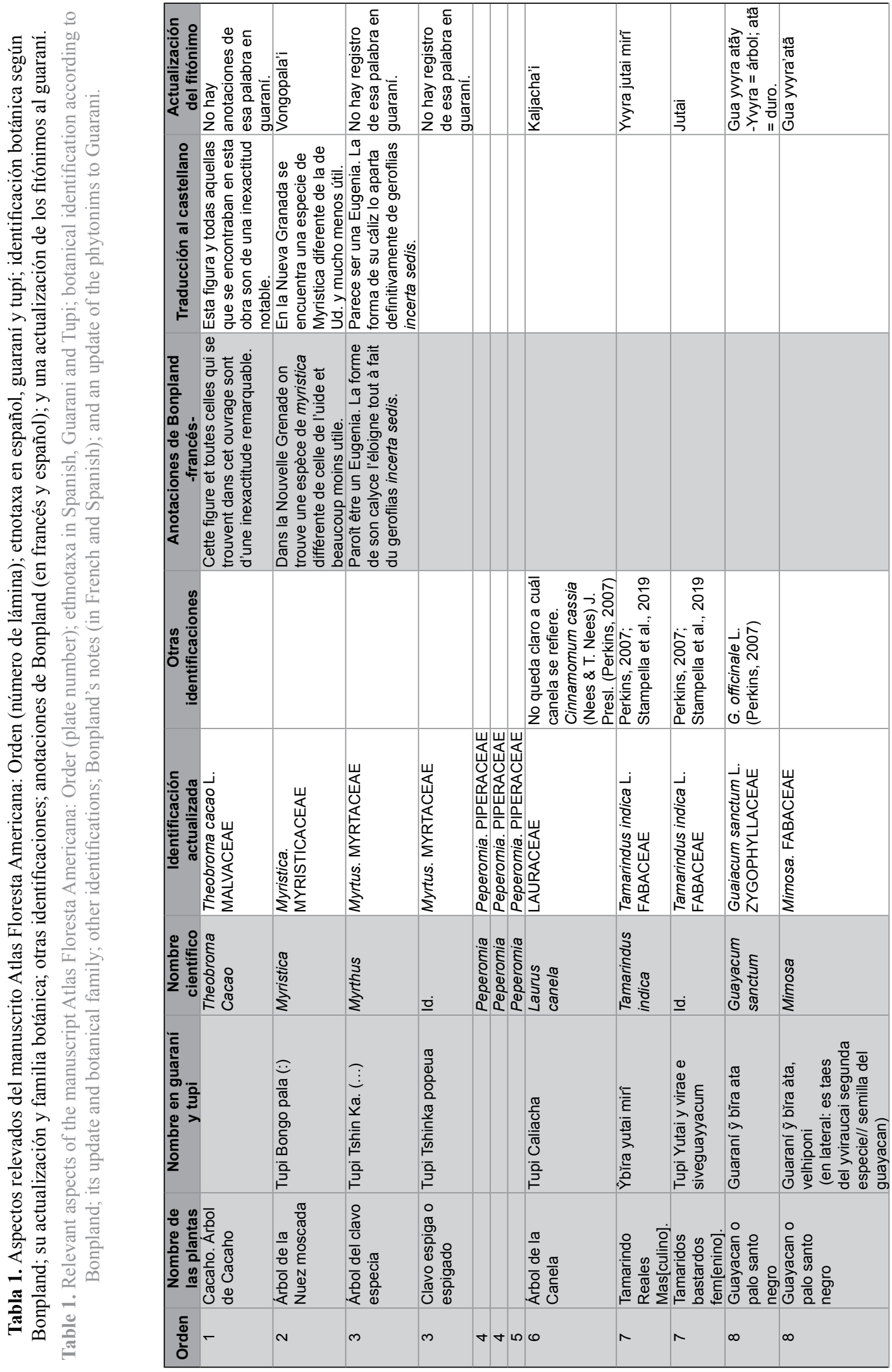


A. Arbelo et al., Atlas Floresta Americana, Bonpland, 1850

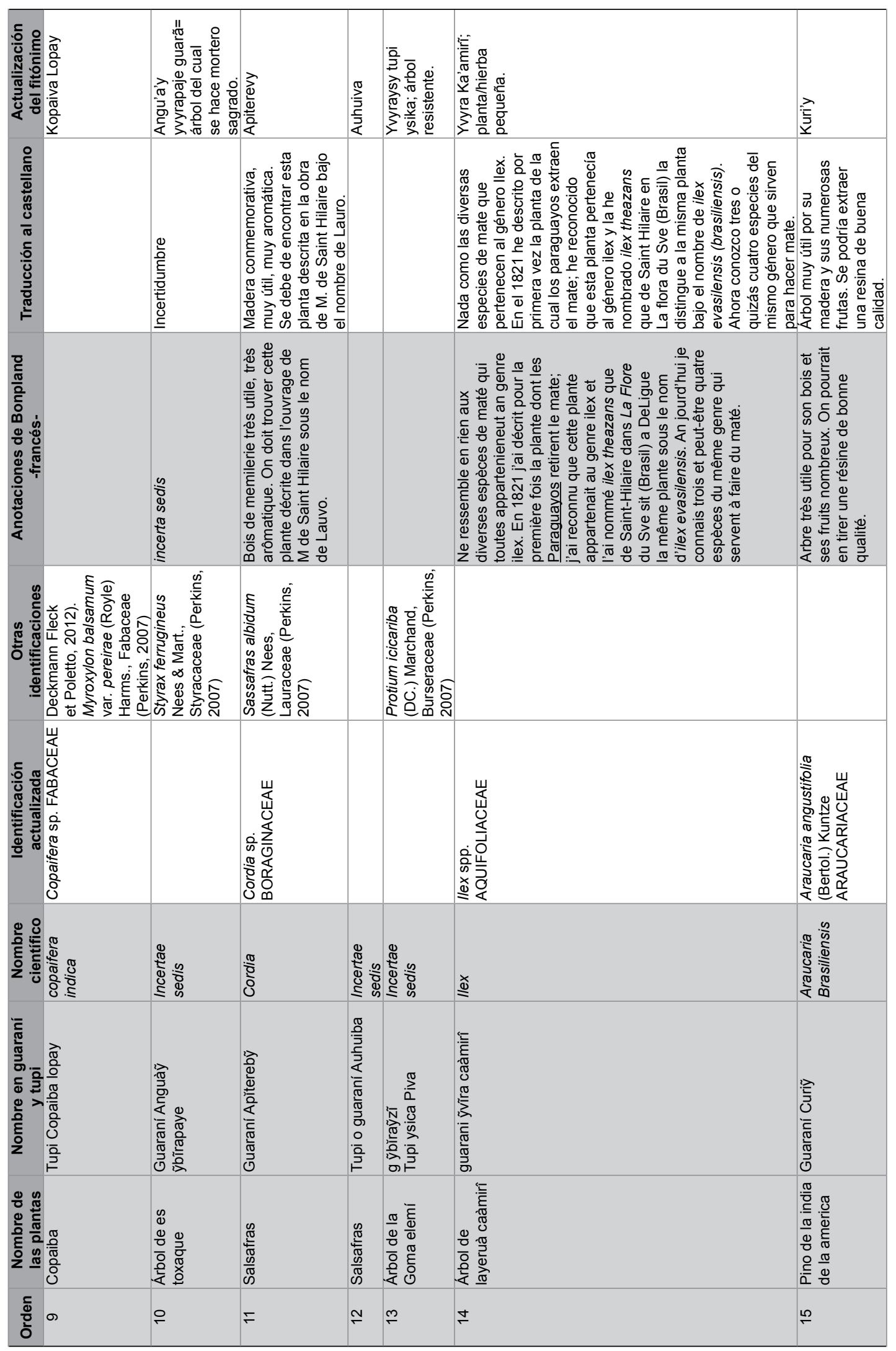




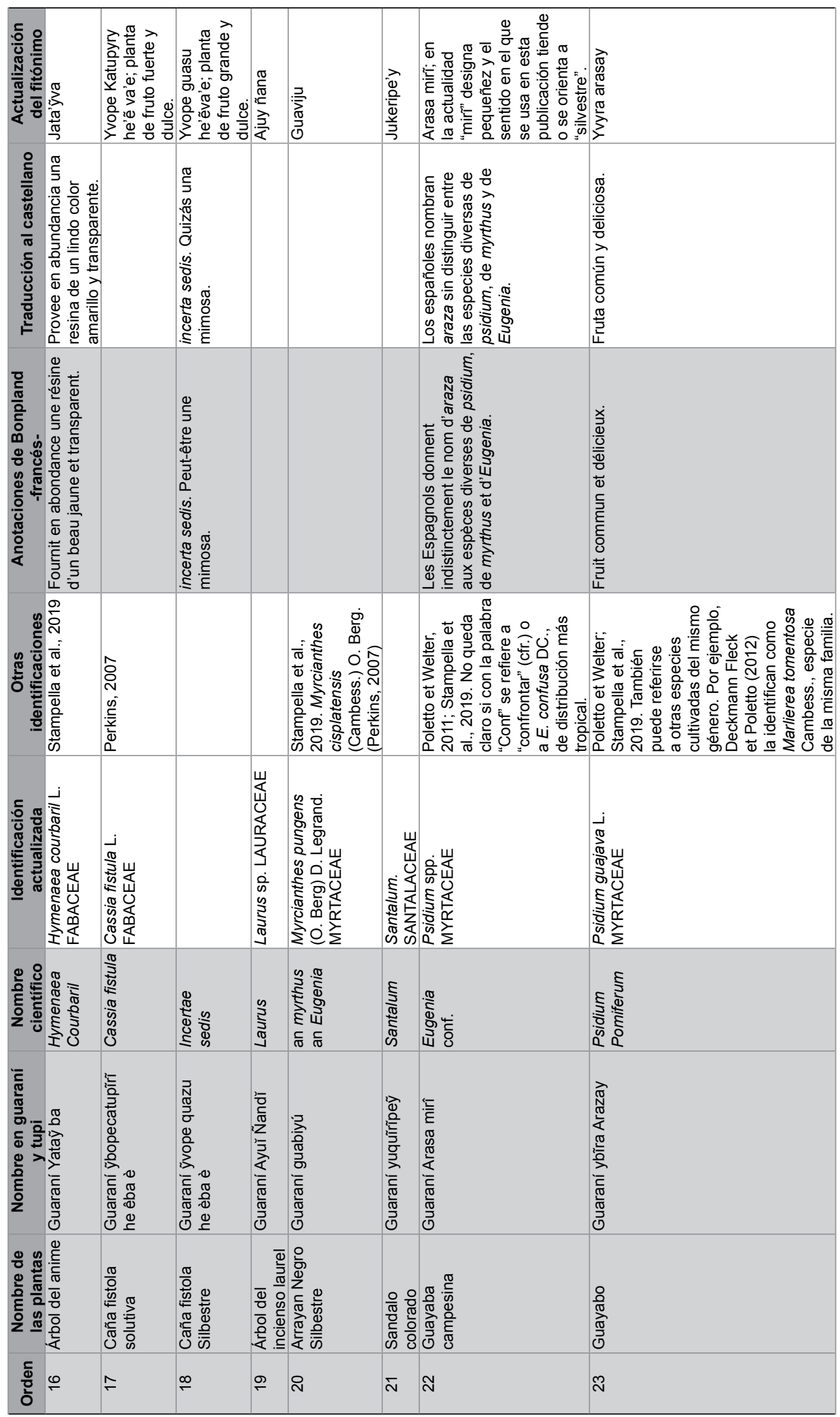




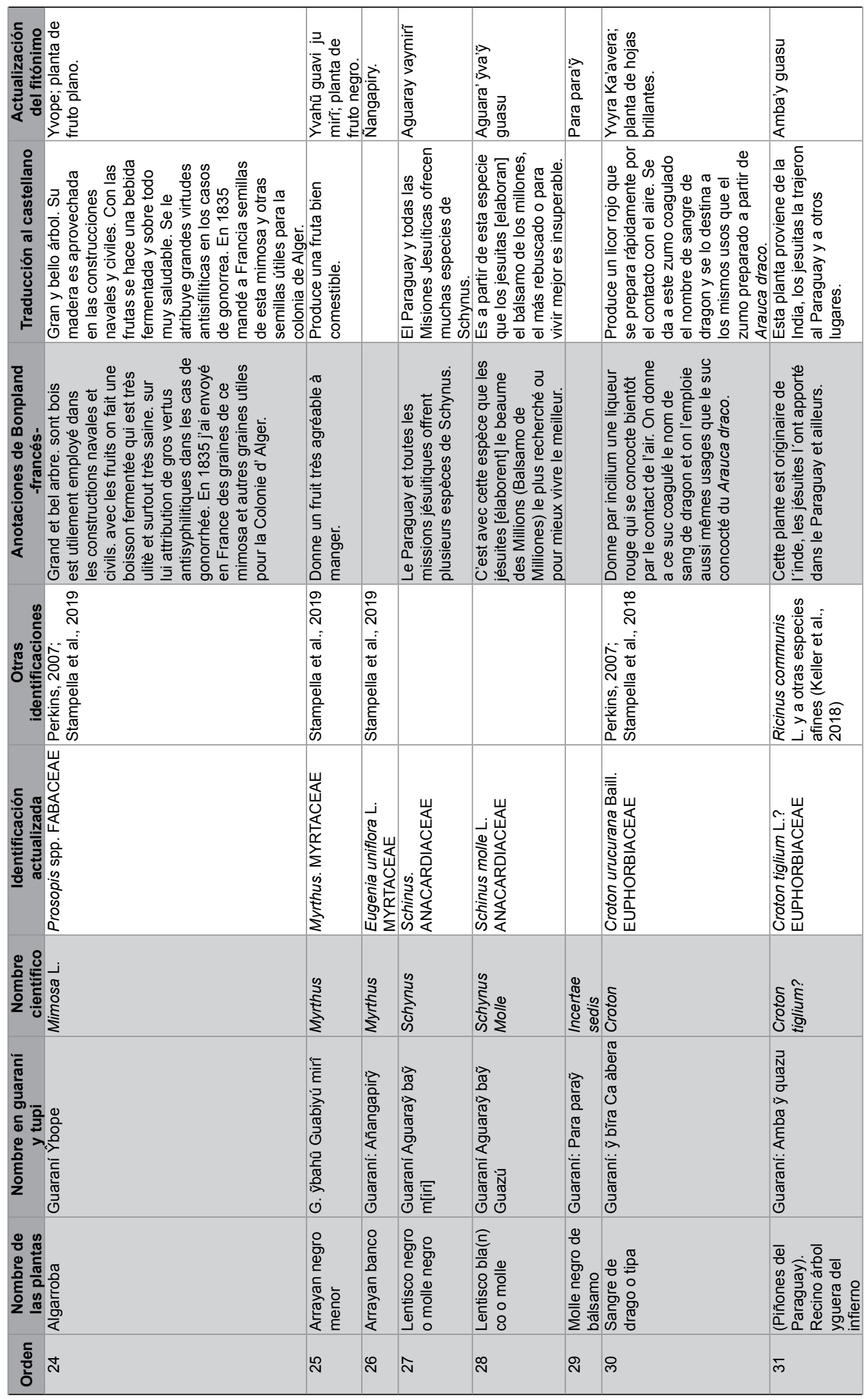




\begin{tabular}{|c|c|c|c|c|c|c|c|c|c|}
\hline 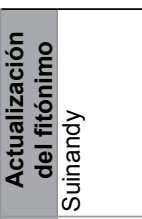 & 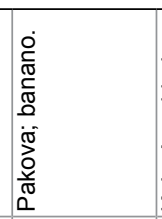 & 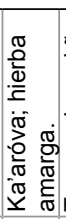 & & 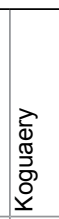 & 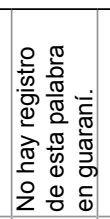 & 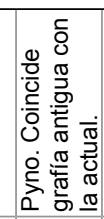 & 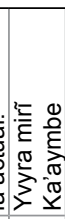 & 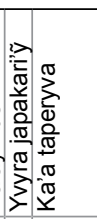 & 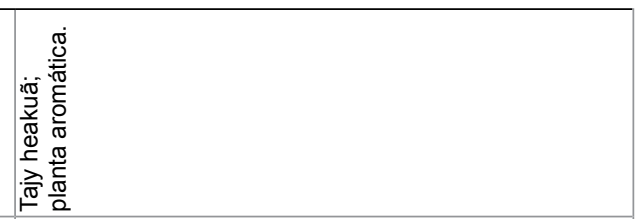 \\
\hline 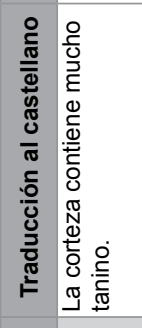 & 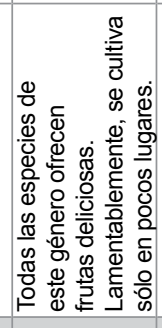 & & & & & 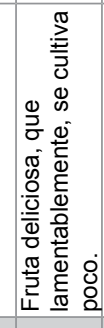 & & 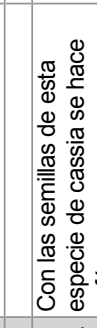 & 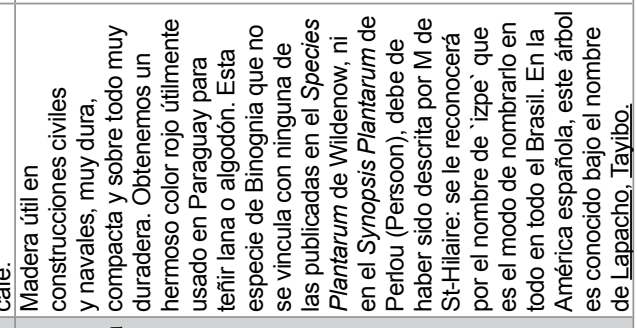 \\
\hline 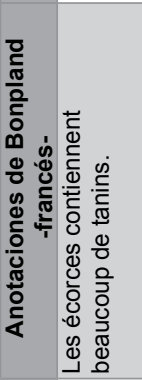 & 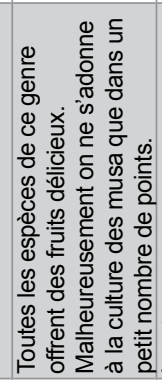 & & 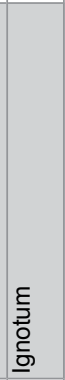 & $\begin{array}{l}\underline{E} \\
\underline{\underline{z}} \\
\underline{0} \\
\underline{0}\end{array}$ & & 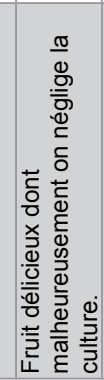 & & 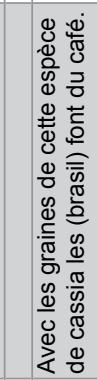 & 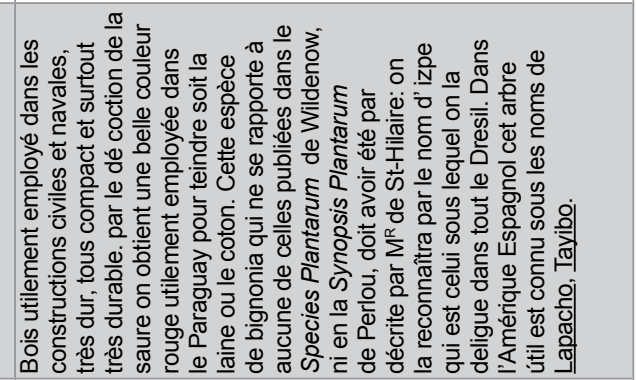 \\
\hline 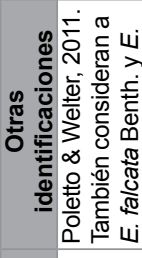 & 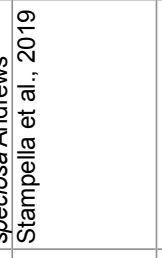 & & & & & 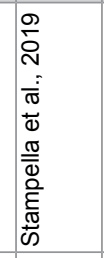 & & & 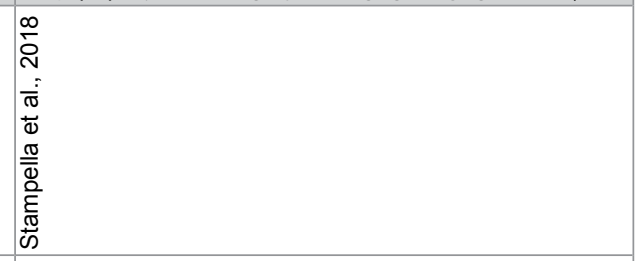 \\
\hline 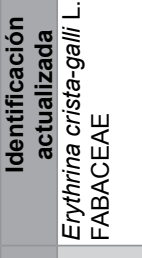 & 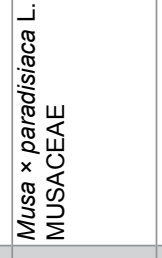 & & & & 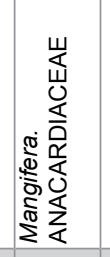 & 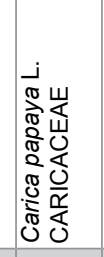 & & 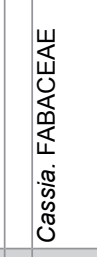 & 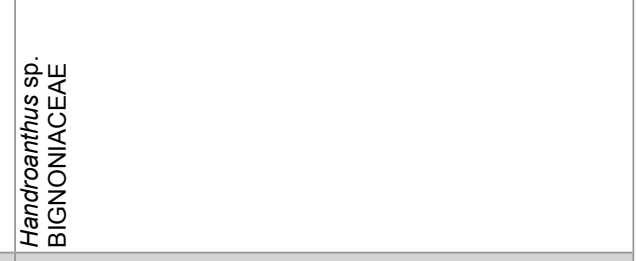 \\
\hline 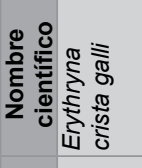 & $\begin{array}{l}\mathbb{Z} \\
ٍ \\
\sum\end{array}$ & $\begin{array}{l}\text { క్ } \\
\text { ప్ } \\
\text { ఏ్ }\end{array}$ & $\begin{array}{l}\text { క్ } \\
\text { ప̊ } \\
\text { ఏ్ }\end{array}$ & 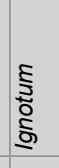 & 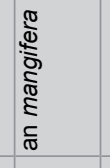 & 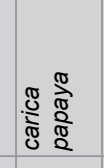 & 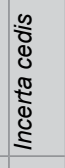 & 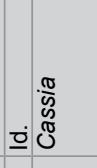 & 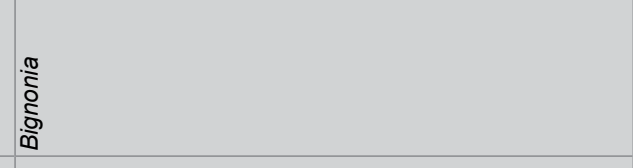 \\
\hline 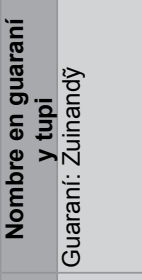 & 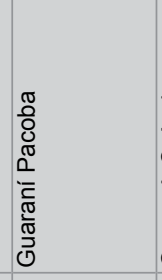 & 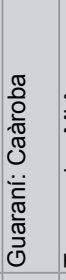 & 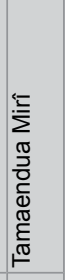 & 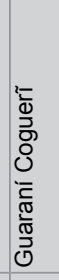 & 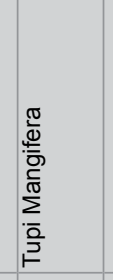 & 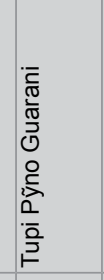 & 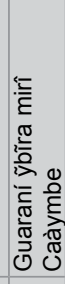 & 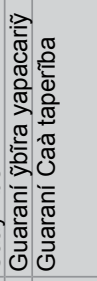 & 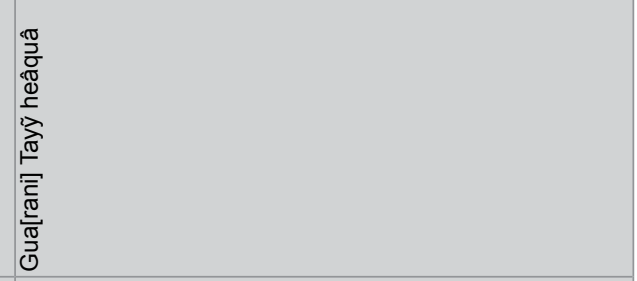 \\
\hline 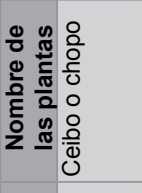 & 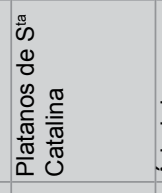 & 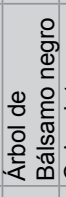 & & & 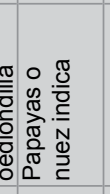 & 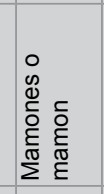 & & 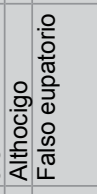 & 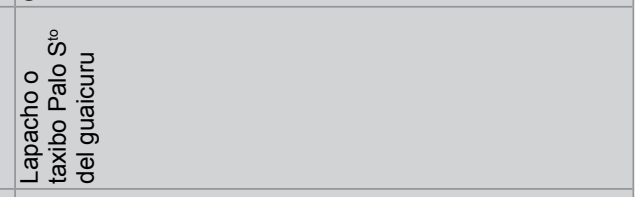 \\
\hline 离 & ભ & ले & ळ & @్ల & $\hat{m}$ & $\stackrel{\infty}{\infty}$ & ब্ & qテ & ร \\
\hline
\end{tabular}




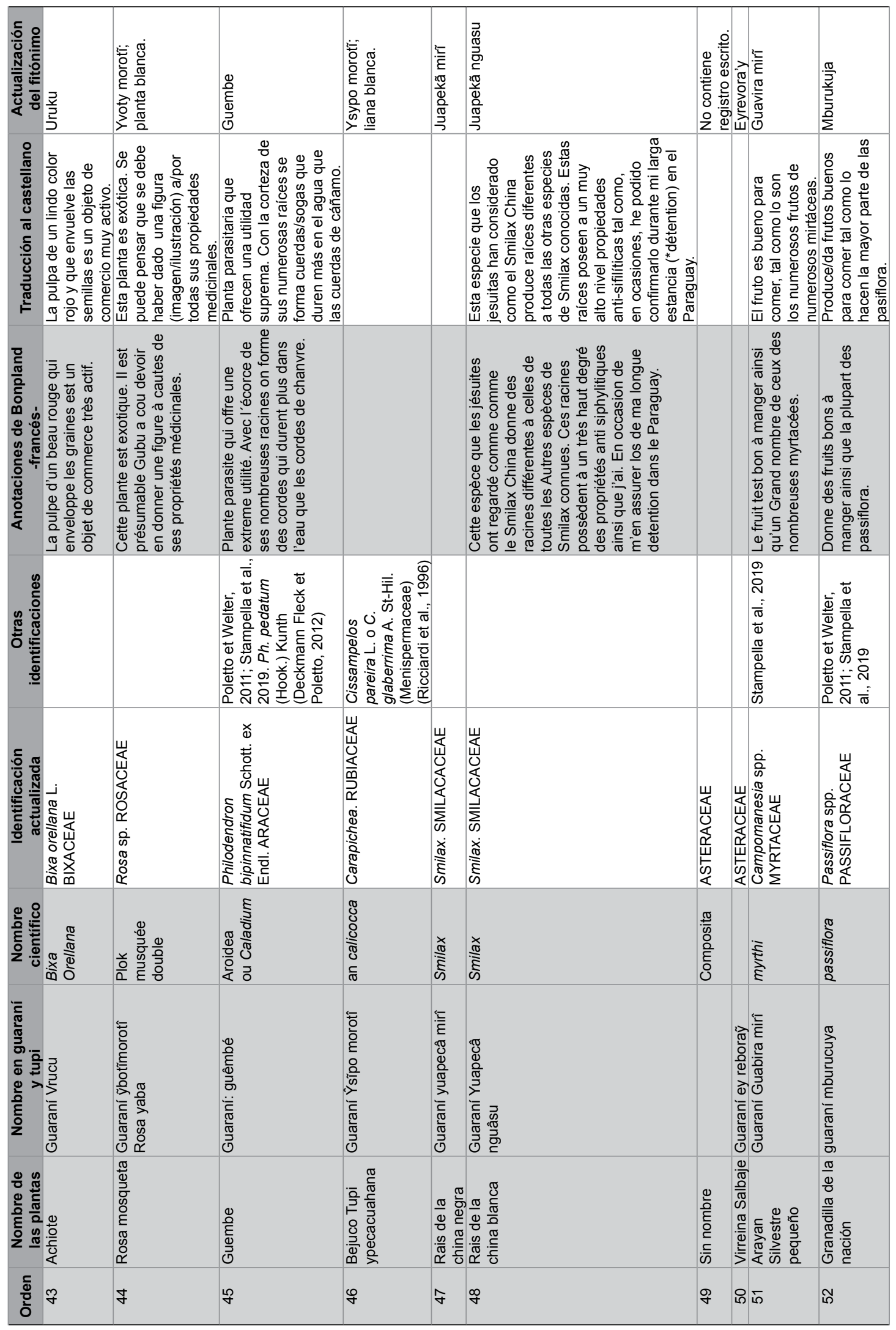




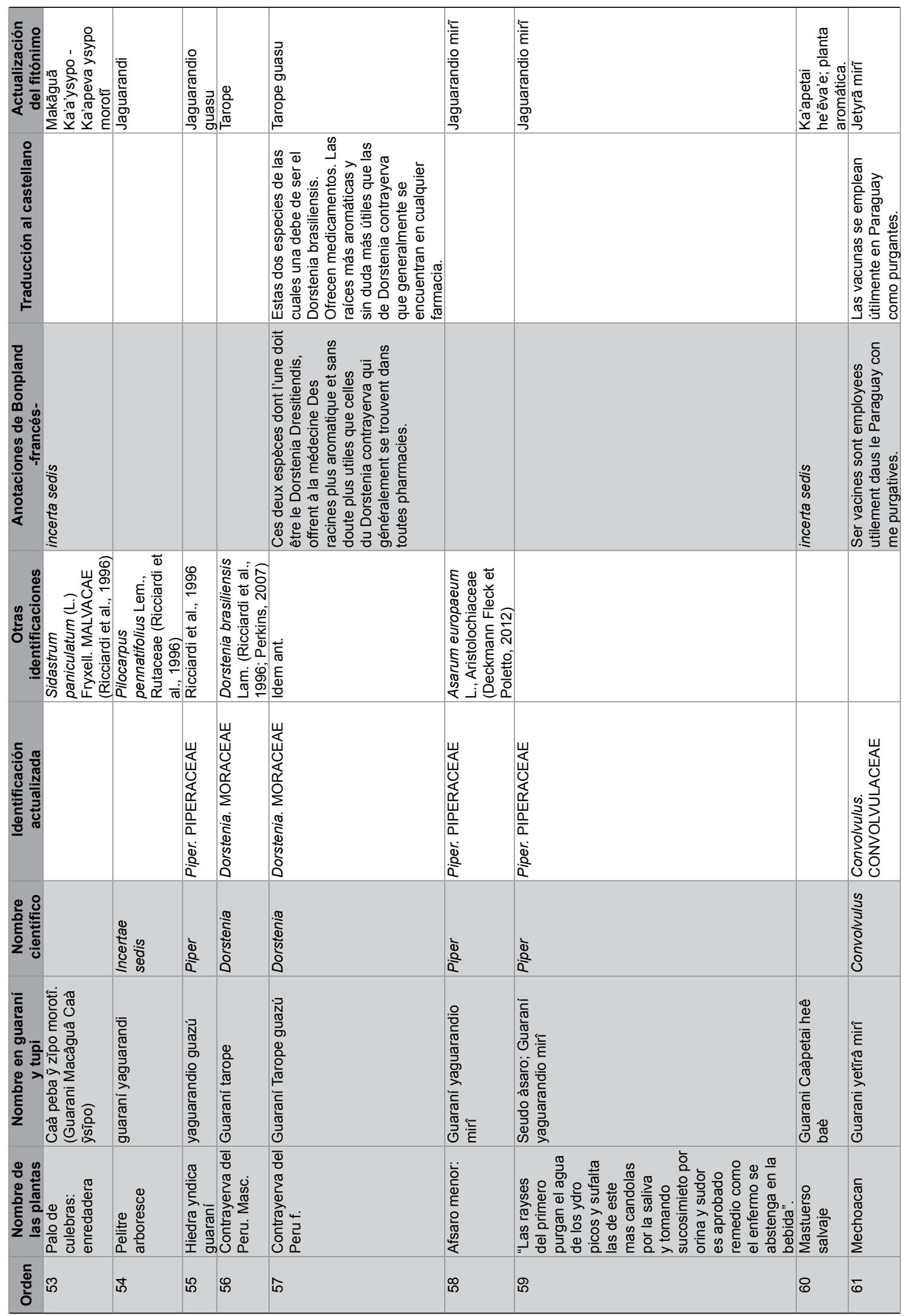




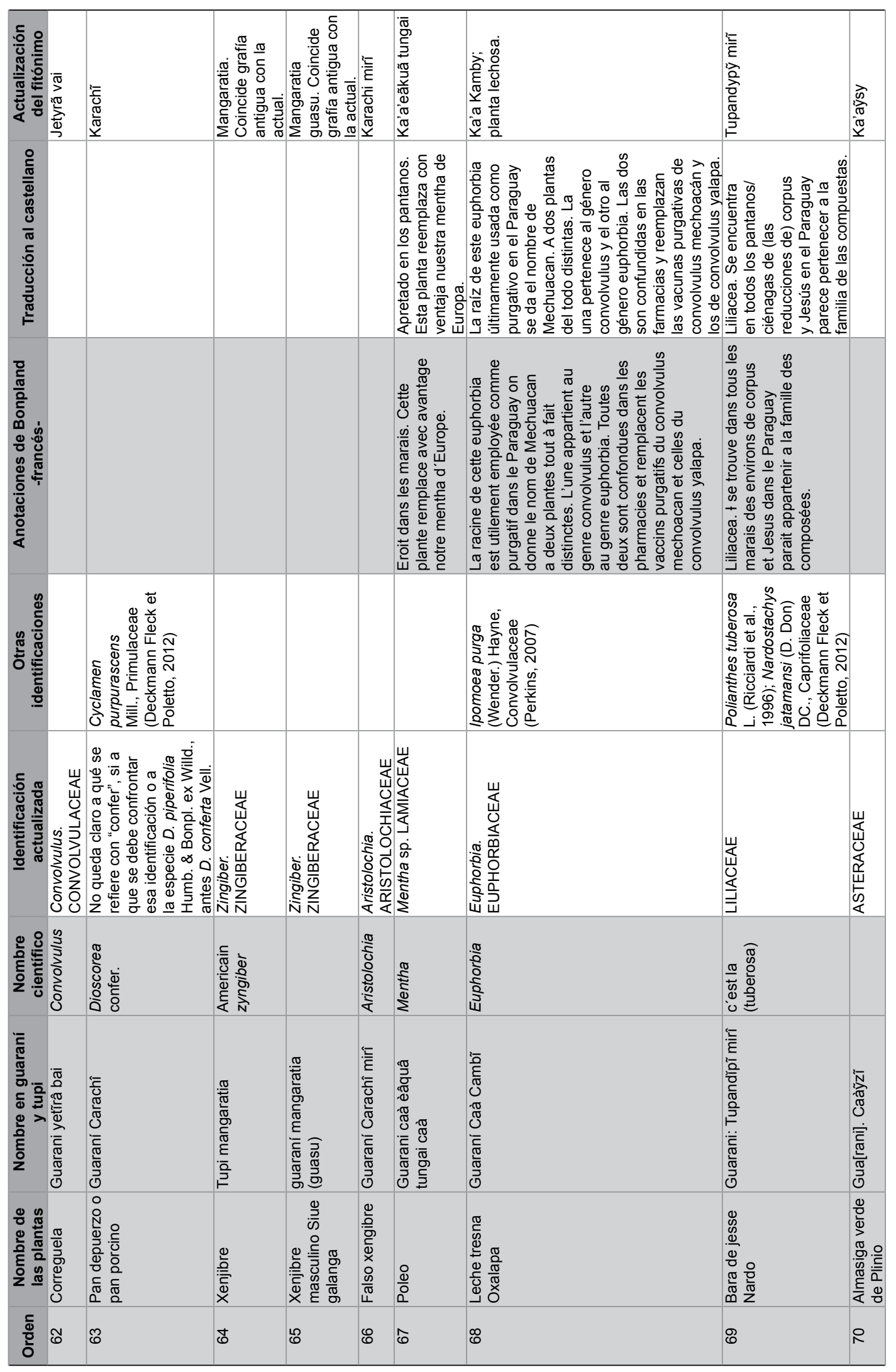




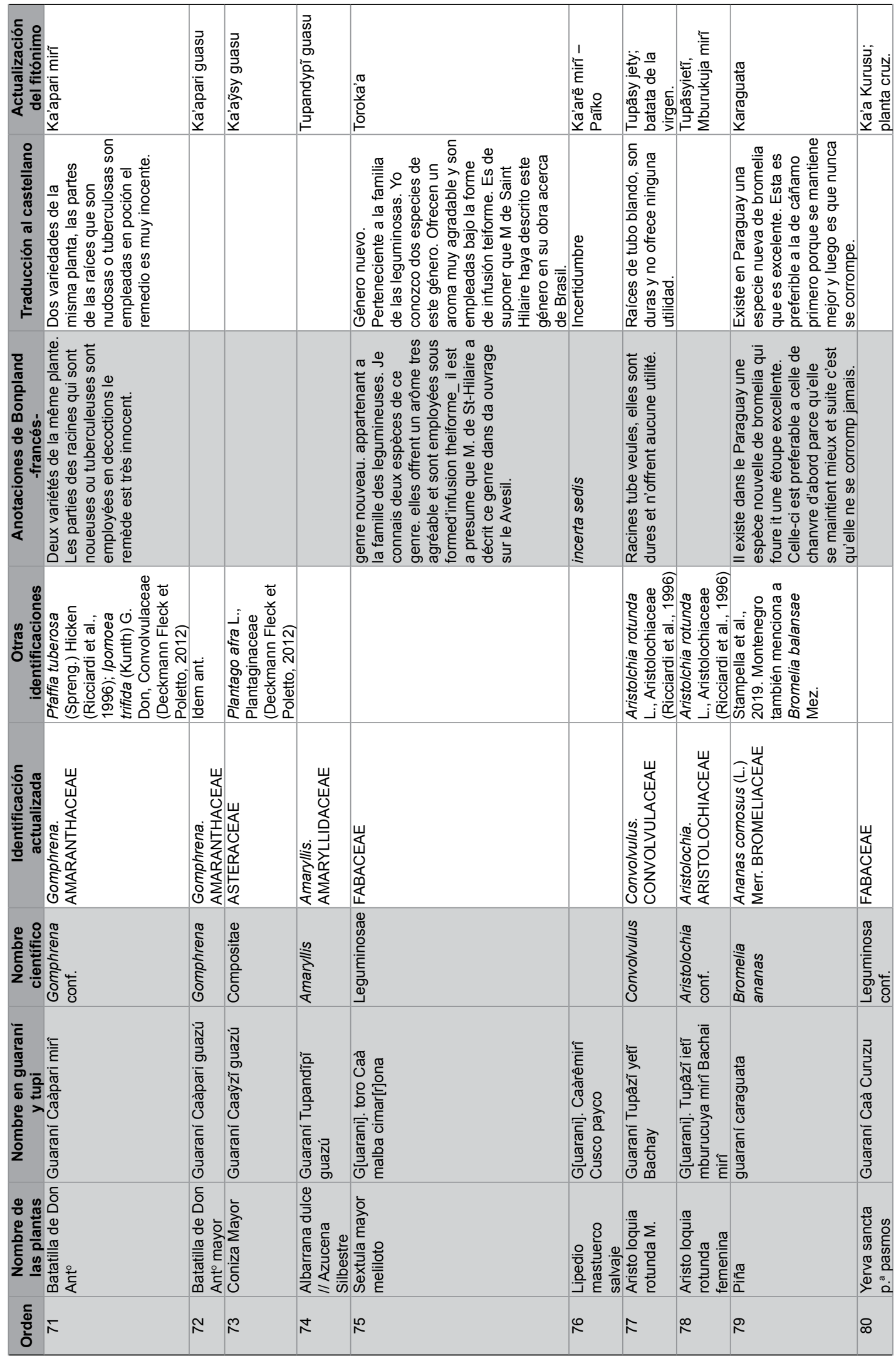




\begin{tabular}{|c|c|c|c|c|c|c|c|c|c|}
\hline 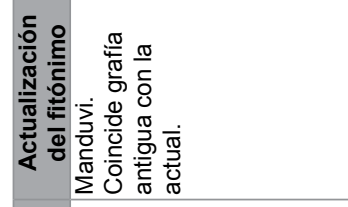 & $\frac{\stackrel{8}{\pi}}{\sqrt{\pi}}$ & 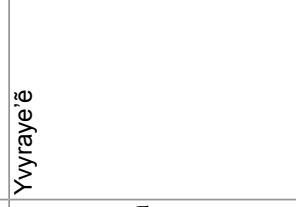 & 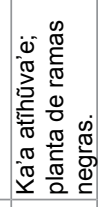 & 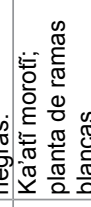 & & 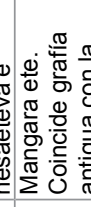 & 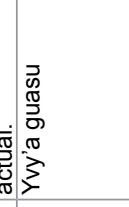 & 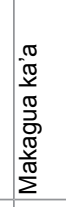 & 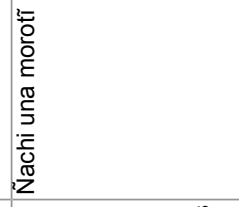 \\
\hline 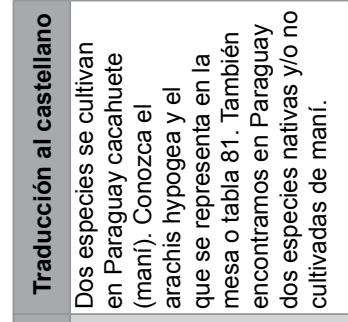 & & 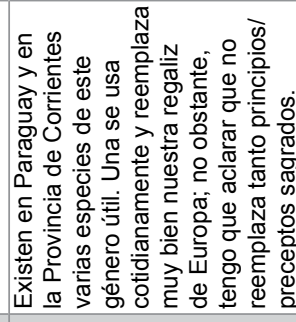 & & & & & 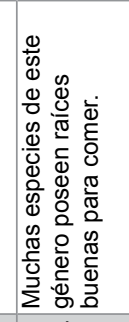 & 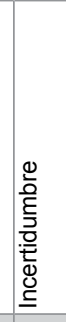 & 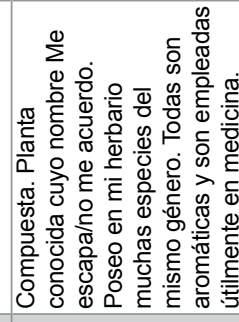 \\
\hline 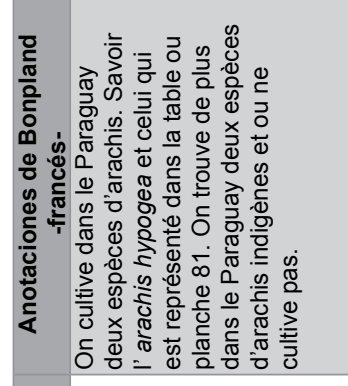 & & 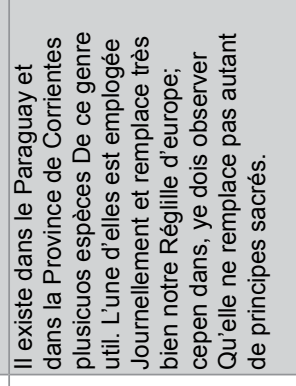 & $\begin{array}{l}\frac{\pi}{0} \\
\frac{0}{0} \\
\frac{0}{E} \\
\text { ठ } \\
\end{array}$ & & & & 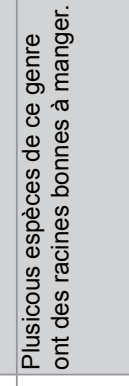 & 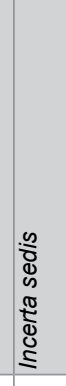 & 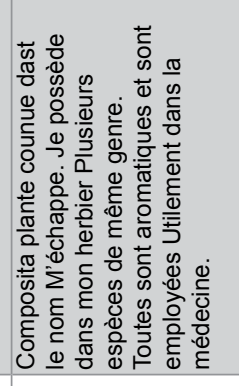 \\
\hline 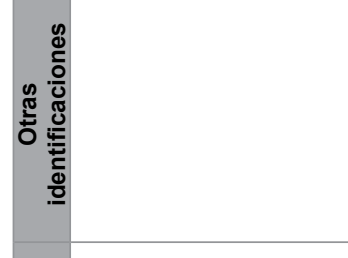 & & 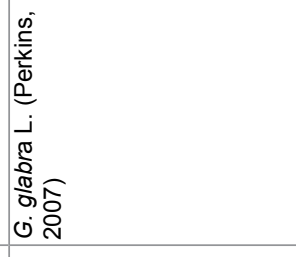 & & & & & 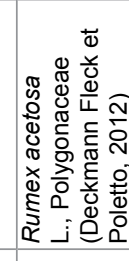 & & \\
\hline 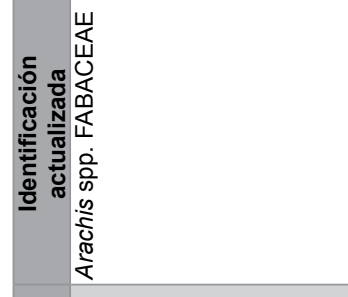 & 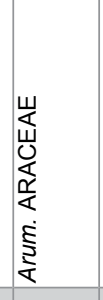 & 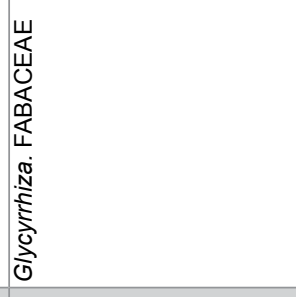 & 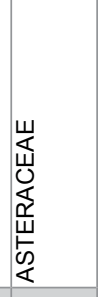 & 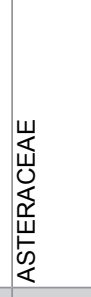 & 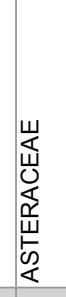 & 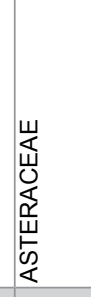 & 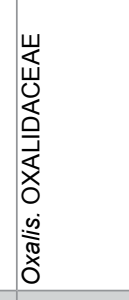 & & 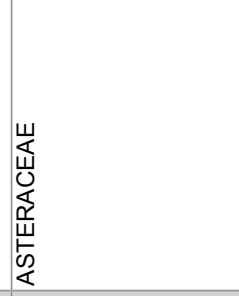 \\
\hline 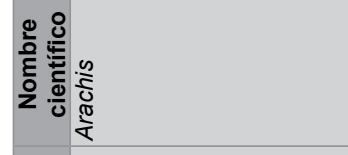 & 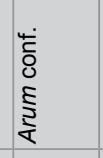 & 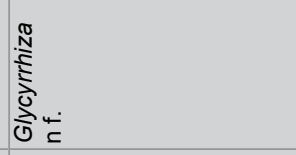 & & & & & $\frac{0}{\tilde{\pi}}$ & & \\
\hline 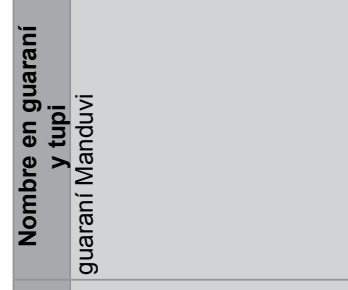 & 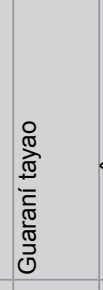 & 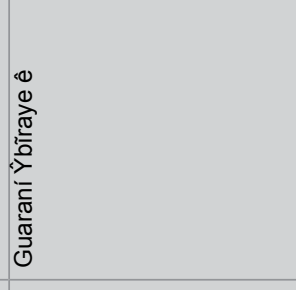 & 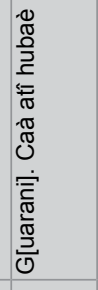 & 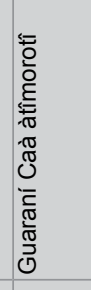 & 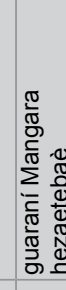 & 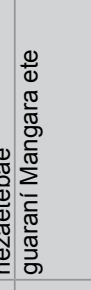 & 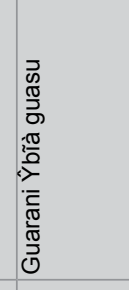 & 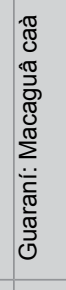 & 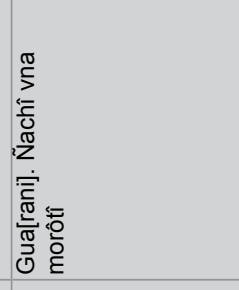 \\
\hline 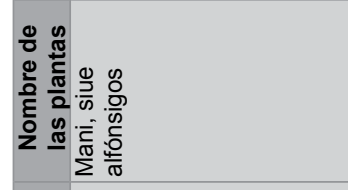 & 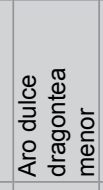 & 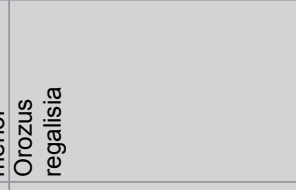 & 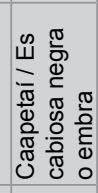 & 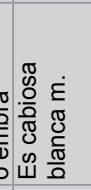 & 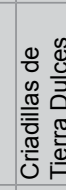 & 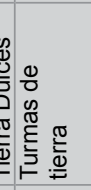 & 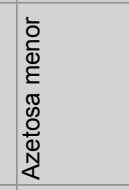 & 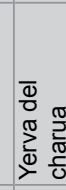 & 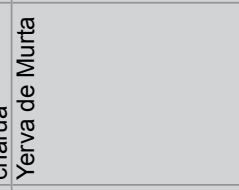 \\
\hline 离 $\bar{\varnothing}$ & $\infty$ & $\infty$ & ळ & 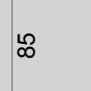 & $\infty$ & $\hat{\infty}$ & $\infty$ & ஃ & ৪ \\
\hline
\end{tabular}




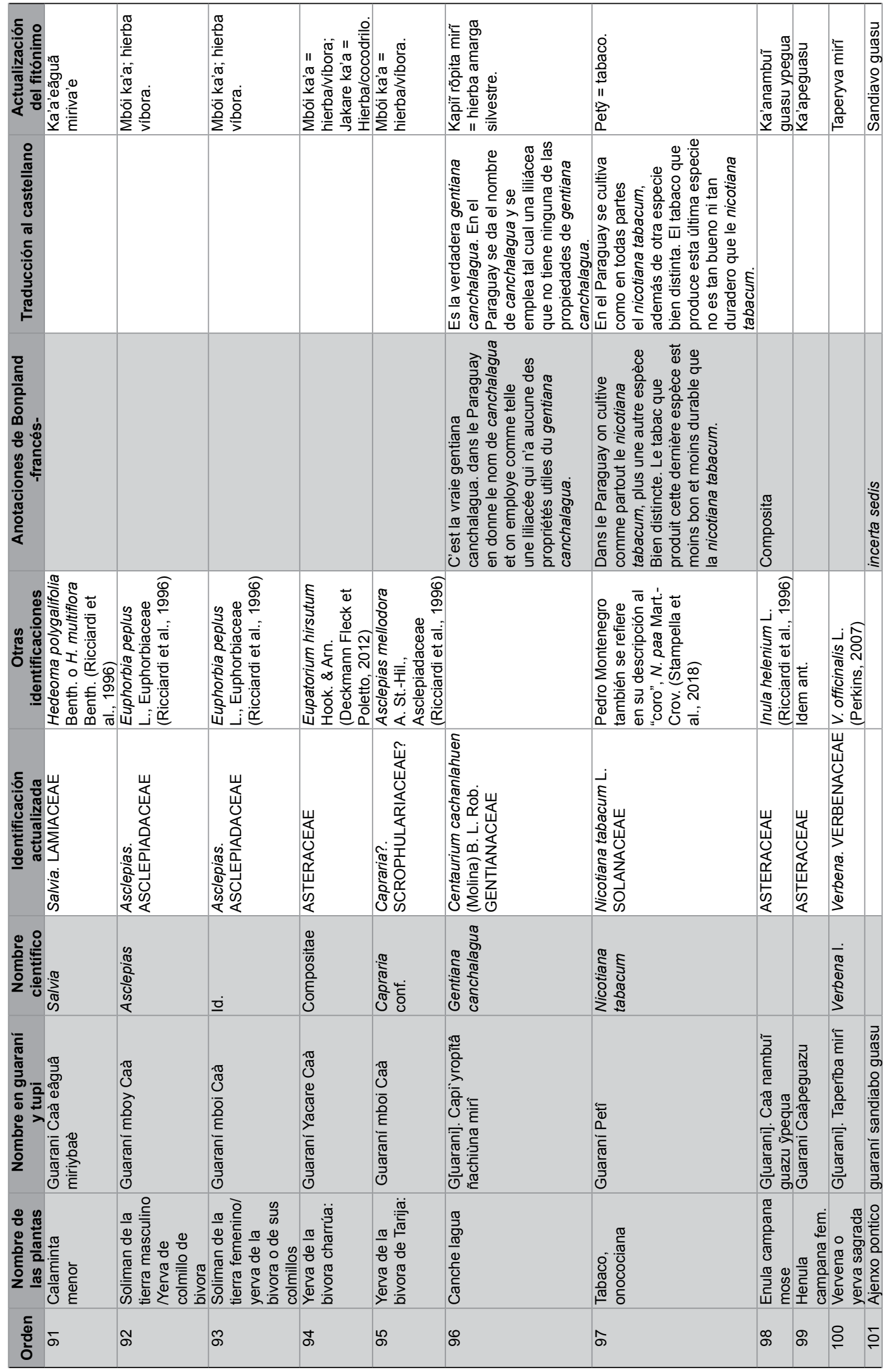


A. Arbelo et al., Atlas Floresta Americana, Bonpland, 1850

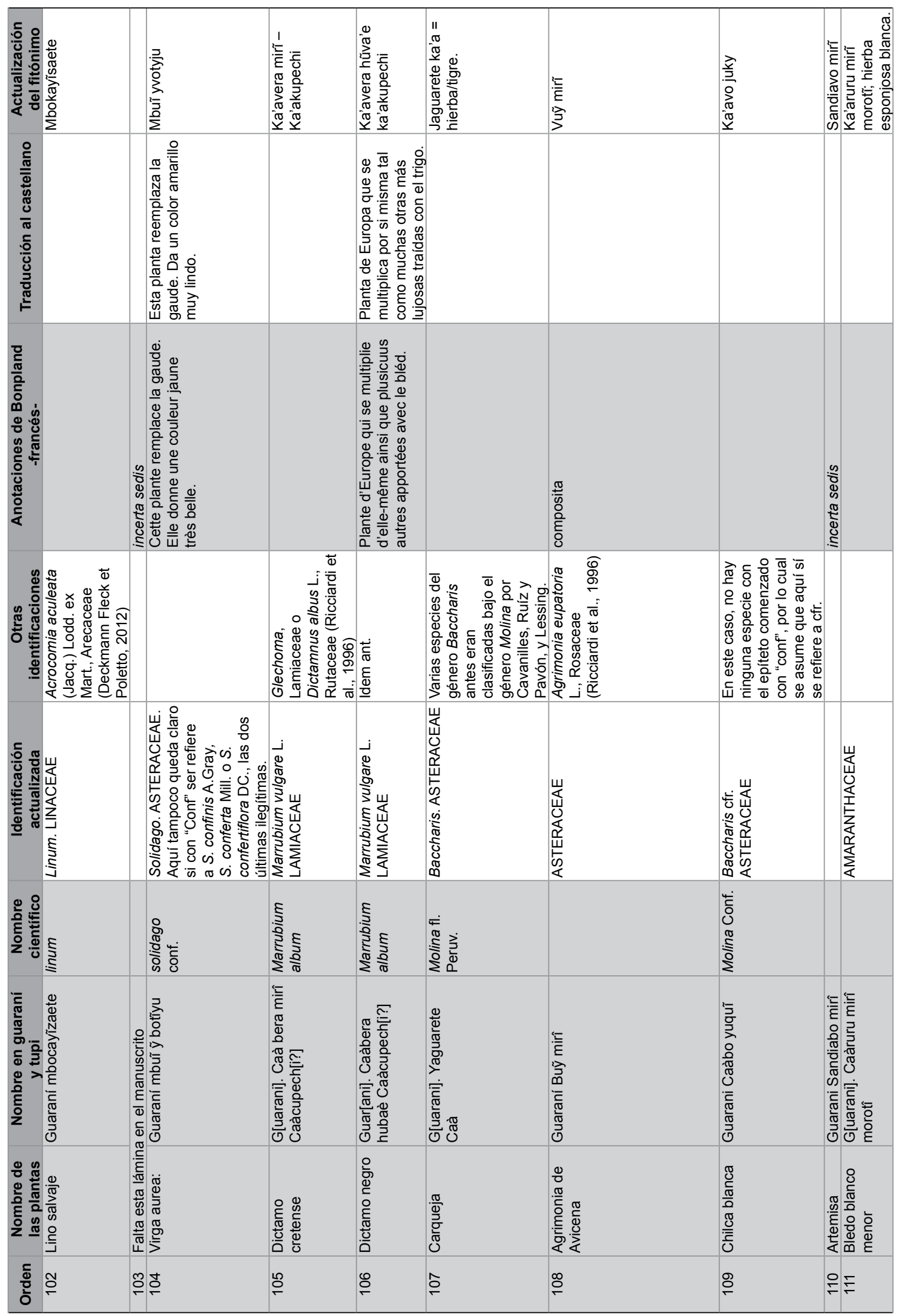




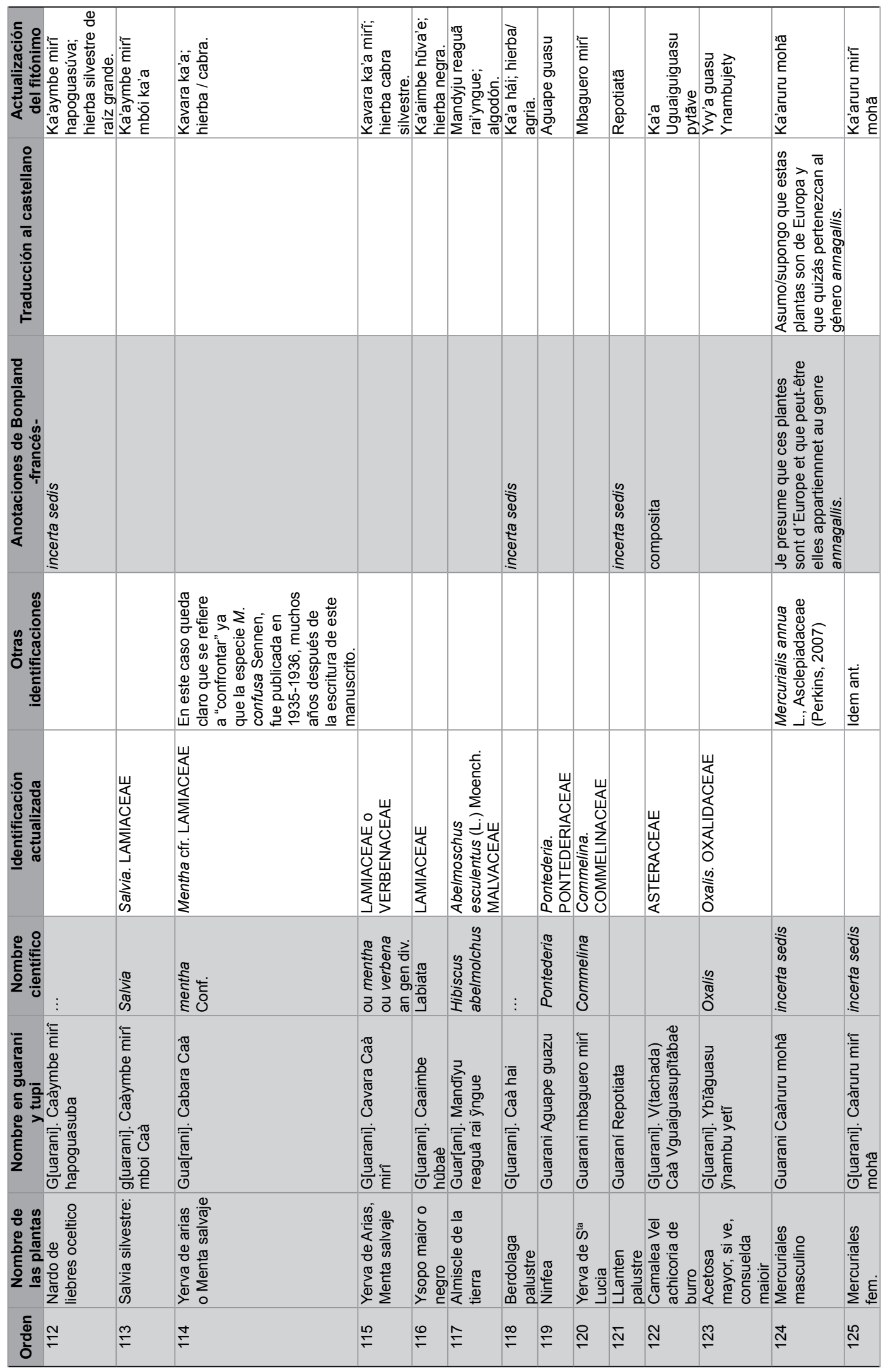


A. Arbelo et al., Atlas Floresta Americana, Bonpland, 1850

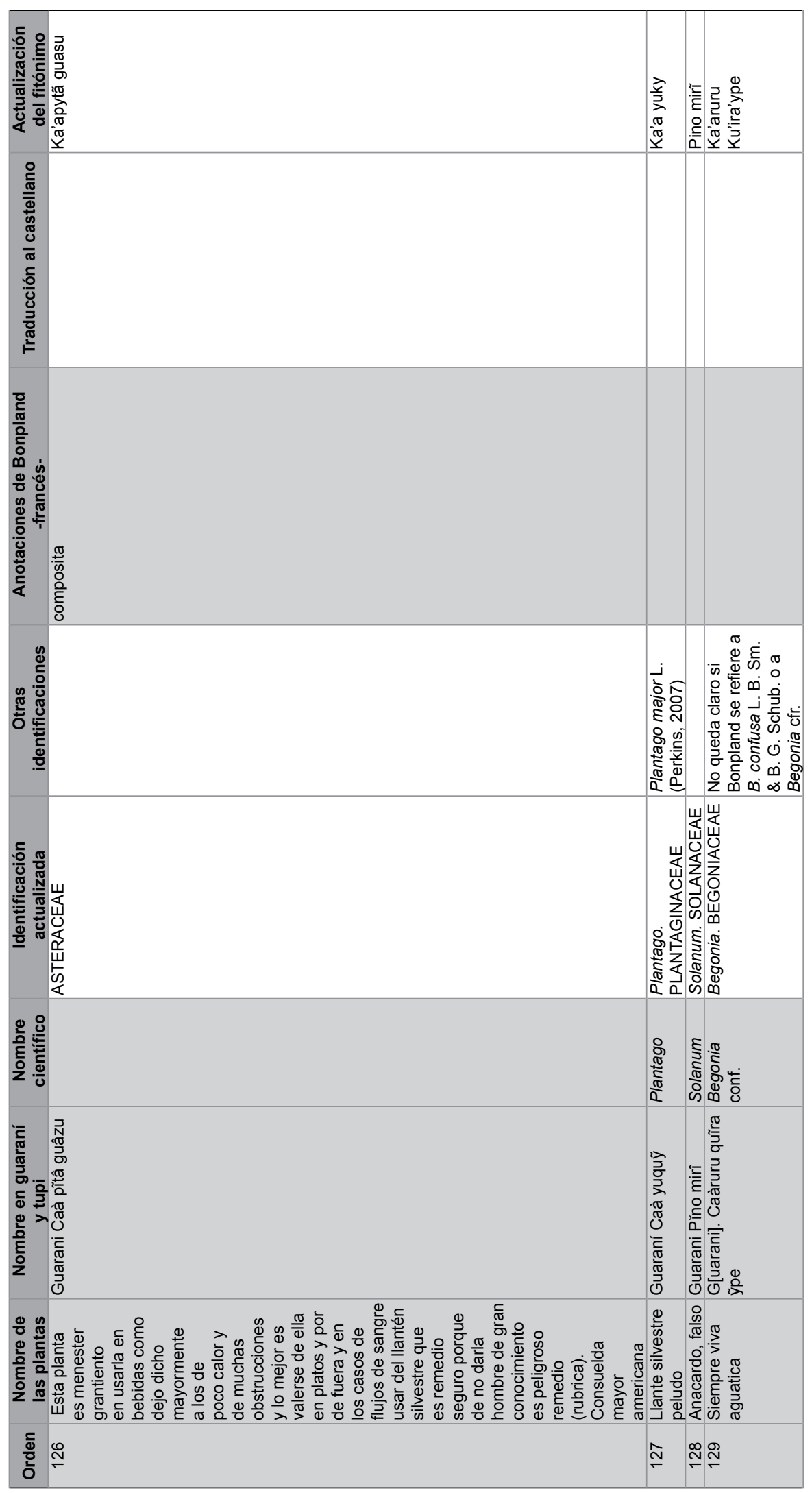




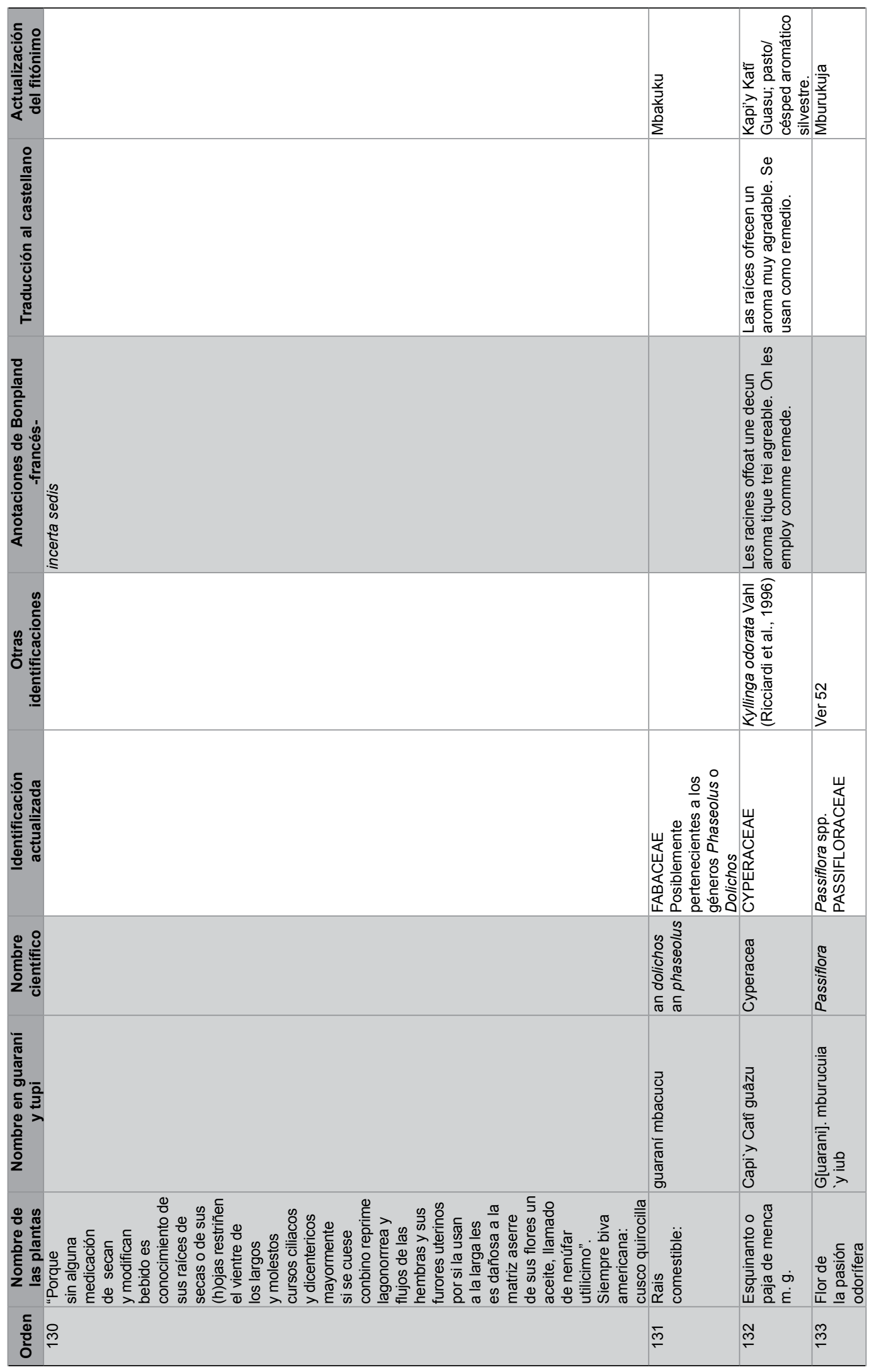


A. Arbelo et al., Atlas Floresta Americana, Bonpland, 1850

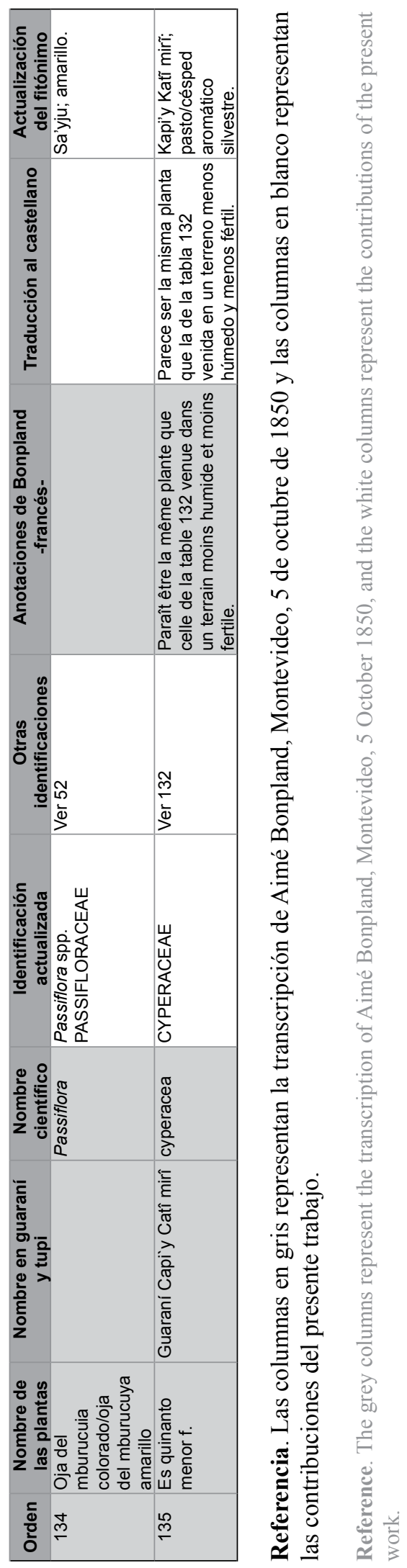



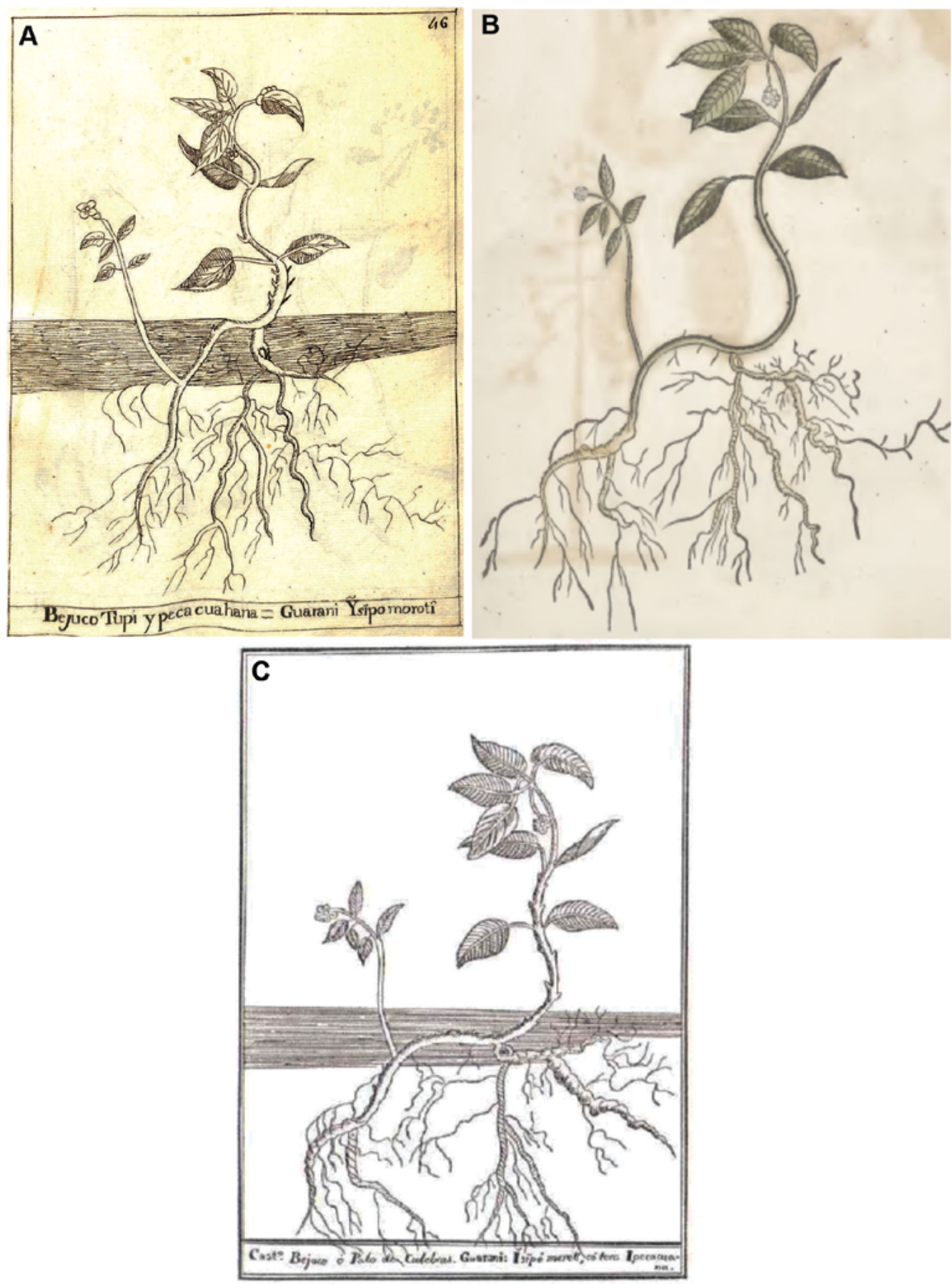

Fig. 3. Comparación de la lámina 46 del manuscrito de A. Bonpland con las correspondientes de W. Piso y Pedro de Montenegro. A: Lám. 46, Bonpland, "Bejuco Tupi y pecacuhana = Guarani Ŷsĩpo morotî”. B: W. Piso, Cap. IX, p. 17, "Ipecacoanha”. C: Lám. LXX, Pedro Montenegro, p. 263, "Bejuco o Palo de Culebras. Guaraní: Isipo morotí, có terá, Ipecacuana".

Fig. 3. Comparison of plate 46 of A. Bonpland's manuscript with the corresponding ones of W. Piso and Pedro de Montenegro. A: Pl. 46, Bonpland, «Bejuco Tupi y pecacuhana = Guarani Ŷsĩpo morotî». B: W. Piso, Ch. IX, p. 17, «Ipecacoanha». C: Pl. LXX, Pedro Montenegro, p. 263, «Bejuco o Palo de Culebras. Guaraní: Isipo morotí, có terá, Ipecacuana». 


\section{Conclusiones}

Teniendo en consideración que hasta la fecha los manuscritos bonplandianos permanecen mayormente inéditos, la contribución al conocimiento y difusión del Atlas Floresta Americana, que fue posible gracias a las mediaciones de Sara Bolaños y la iniciativa de la Dirección de Relaciones Internacionales, del Museo de Ciencias Naturales y de la Asociación Civil Cultural Bonpland de Corrientes, sin duda constituye un aporte fundamental para dimensionar de manera más integral el legado de Bonpland.

La auspiciosa cooperación internacional, interinstitucional e interdisciplinaria, nos permite conocer cuanto ha aportado Amado Bonpland a la floresta americana ya que se conoce vastamente su trayectoria histórica, política y social pero no la científica.

Asimismo el presente trabajo revaloriza este manuscrito como patrimonio documental único, enriqueciendo el campo teórico y explicitando los procesos que involucran a diferentes grupos de opinión.

En el año 1850, fecha del legado de A. Bonpland del Atlas Floresta Americana, envió correspondencias, colectó y describió especies vegetales en Montevideo.

Finalmente, cabe destacar que a través de un examen visual detallado, podrían conocerse características estructurales del Atlas y los materiales que lo conforman, así como el tipo documental, marcas de agua, estudio de las tintas, entre otras, que podrían generar una vinculación comparativa con documentación de la misma fecha y espacio geográfico, aportando otros datos que enriquecerían esta investigación.

En cuanto a la descripción del estado de conservación, podría diagnosticarse el estado de cada parte material según aspectos físicos, químicos y biológicos del Atlas, además de una descripción global del mismo. Como proyección futura, podría continuarse con estos aspectos mencionados, colaborando así con la propuesta de tratamientos de intervención, que apuesten a la conservación de este patrimonio documental.

El naturalista francés superó su propia existencia individual para denotar su presencia en las ciencias americanas, institucionalizando el conocimiento científico en términos modernos.
Es indudable que Amado Bonpland fundó una tradición en el ámbito específico en el cual desplegó su acción, contribuyendo a generar una actividad científica en el Plata, acorde con las aspiraciones de los incipientes Estados provinciales. Asimismo, su manifiesto interés tanto en ramas taxonómicas como aplicadas de la Botánica parece haber presagiado el perfil y la diversidad de contribuciones publicadas que caracterizan a la revista que lo honra: Bonplandia.

\section{Infomación complementaria}

La copia digital del Manuscrito Floresta Americana - Atlas, puede encontrarse en línea en: http://dx.doi.org/10.30972/bon.2924451

\section{Agradecimientos}

En este trabajo destacamos la colaboración de la Lic. María Cecilia Puigbó quien tuvo a su cargo la comunicación y coordinación entre los diferentes autores que sumaron aportes y permitieron la concreción de este artículo multidisciplinario. Se agradece a la Dra. María Laura Salinas por haber supervisado la tarea de transcripción y traducción del francés al español realizada por los autores del Instituto de Investigaciones Geohistóricas (IIGHI) y en especial a la becaria Milagros Belén Blanco por haber colaborado en la transcripción paleográfica. Se agradece la colaboración de la Prof. Celina Magalí Torres en la interpretación del material en guaraní y a Prof. María Sara Lanari Zubiaur por la lectura del material producido por la Dirección de Educación Intercultural Bilingüe dependiente del Ministerio de Educación de la Prov. de Corrientes. Agradecemos a Sara Bolaños Muñoz de Ecuador y a la Lic. Laura Gabriela Manauta de la Dirección de Cooperación Internacional de la Prov. de Corrientes, por la gestión diplomática en la que se obtuvo la copia del manuscrito de Bonpland enviada desde Quito, Ecuador. Celebramos esta publicación de Bonplandia a quien agradecemos por contribuir al logro de los objetivos propuestos. 


\section{Bibliografía}

AMFBJAD Bs As., Caja No 11, Carpeta No 15, No 1360. Carta de Bonpland a Le Chevalie Gravelle. 8-9

AMFBJAD Bs As., Caja No 15, Carpeta No 1, No 1602. Carta a Sagastume, Fidel. 15.8

AMFBJAD Bs As., Caja No 2, Carpeta $\mathrm{N}^{\circ}$ 6, No 272. Documentos Varios.

AMFBJAD Bs As., Caja No 6, Carpeta No 9, No 786. Cartas de Bonpland a Vicente Porto. 12-8

AMFBJAD Bs As., Caja No 7, Carpeta No 16, No 958. Carta Bonpland a F. Delessert. 30-8

AMFBJAD Bs As., Caja No 7, Carpeta No 17, No 965. Bonpland a Desmarest et Ducoing. 5-11

AMFBJAD Bs As., Caja No 9, Carpeta $\mathrm{N}^{\circ}$ 2, $\mathrm{N}^{\circ} 1152$. Cartas de Bonpland a (?). 28-8

ANAGNOSTOU, S. (2005). Jesuits in spanish America: Contributions to the exploration of the american Materia Medica. Pharmacy in History 47: 3-17.

ARBELO, A. (2012). Presencia de Caraí Arandú en Quito. IV Encuentro Latinoamericano de bibliotecarios, archivistas y museólogos (EBAM). 1-3 de octubre, Buenos Aires.

AZARA, F. DE (1865). Apuntes de varias cosas tendientes a esta provincia (del Paraguay) sacadas del P. S. Asperger exjesuita de esas Misiones del Uruguay y Félix de Azara. AGN, Bs. As.

BCMNHN Francia, Aimé Bonpland. MS 209 "Voyage 1849-1853". Bibliothèque Centrale du Muséum National d'Histoire Naturelle, París, Francia. May 1850, p. 29.

BCMNHN Francia, Aimé Bonpland. MS 210 "Catalogue pour servir a la Géologie des cótes de l'Uruguay, du Parana, de la plata; de toutes les missions jesuitiques, des provinces du Paraguay, de Corrientes, de l'Entre- Rios de la Cisplatine et de la république argentine, par Aimé Bonpland". 1858. Bibliothèque Centrale du Muséum National d'Histoire Naturelle, París, Francia. Reg. 188-223, pp. 54-58.

BELL, S. (1995). Aimé Bonpland in Southern South America, (1817-1858). Stanford University Press, California.

BERRO GARCÍA, A. (1950). Boletín de Filología. Tomo VI, Montevideo, Uruguay.

BONPLAND, A. (1924). Archives Inédites. Journal de Botanique, Tomo 2. Trabajos del Instituto de Botánica y Farmacología. J. Peuser, Buenos Aires.

CANDELA, G. \& MELIÀ, B. (2015). Lenguas y pueblos tupí-guaraníes en las fuentes de los siglos
XVI y XVII. Mélanges de la Casa de Velázquez 45: 57-76. https://doi.org/10.4000/mcv.6129

CARBONELL, R. (1992). Estrategias de desarrollo rural en los pueblos guaraníes (1609-1767). Antoni Bosch, Barcelona.

CASTEX, M. (1968). Sánchez Labrador. Peces y aves del Paraguay Natural ilustrado 1767. Compañía General Fabril Editora, Buenos Aires.

CERRUTI, C. (2012). L'américanisme en construction. Une pré-histoire de la discipline d'après l'expérience du naturaliste Aimé Bonpland (1773-1858). Doctorado en Historia, FLLASH, Universidad de La Rochelle. 978 pp.

DECKMANN FLECK, E. C. \& POLETTO, R. (2012). Circulation and production of knowledge and scientific practices in southern America in eighteenth century: an analysis of Materia medica misionera, an manuscript by Pedro Montenegro (1710). História, Ciências, Saúde - Manguinhos 19: 1-17. https://doi.org/10.1590/S0104-59702012000400002

DÍAZ PIEDRAHITA, S. (2001). La botánica y el viaje de Humboldt y Bonpland. En HOLL, F. (ed.), El regreso de Humboldt, pp. 67-78. Asociación Humboldt - Instituto Goethe, Quito.

FOUCAULT, Ph. (1994). El pescador de orquídeas. Emecé Ed., Buenos Aires.

FURLONG, G. (1948). Naturalistas argentinos durante la dominación hispánica. Ed. Huarpes, Buenos Aires.

FURLONG, G. (1969). Nuevos datos sobre Bonpland en Buenos Aires (1818). Anales de la Universidad del Salvador 5: 133-147.

GIBERTI, G. (2008). El Archivo Bonpland en el Museo de farmacobotánica "Juan Aníbal Domínguez". Dominguezia 24: 5-9.

HERRERA CRESPO, P. (2013). Libro del siglo XVIII. Bonpland descubrió la Floresta americana. Casapalabras. Revista de la Casa de la Cultura Ecuatoriana "Benjamín Carrión" 3: 34-36.

HOLL, F. (2001). El regreso de Humboldt. Asociación Humboldt - Instituto Goethe, Quito.

IBARRA, M. F. (2007). El Padre Pedro de Montenegro, 1700. Su tratamiento de herboristería para las afecciones mentales y sus referencias a la medicina hipocrático-galénica. XIV Jornadas de Investigación y Tercer Encuentro de Investigadores en Psicología del Mercosur. Disponible: https:// www.aacademica.org/000-073/71.pdf. (Consulta: 03/02/18).

KELLER, H. A., PIRONDO, A. \& STAMPELLA, P. C. (2018). El cultivo del ricino y el amba'y en 
comunidades guaraníes del nordeste argentino, aproximación etnobotánica de su historia y cosmología. Bonplandia 27: 23-30.

https://doi.org/10.30972/bon.2712983

LE PATRIOTE FRANCAIS. (1849). (http:// bibliotecadigital.bibna.gub.uy: $8080 /$ jspui/ bitstream/123456789/44009/1/patrioteFR2432.pdf)

MARTÍNEZ, M., BARBEITO, A. P. \& BOLAÑOS, R. (1990). La influencia jesuítica en la farmacología. Signos Universitarios 9: 51-57.

MELIÀ, B. (1992). La lengua guaraní del Paraguay: historia, sociedad y literatura. Ed. MAPFRE, Madrid.

MELIÀ, B. (2003). La lengua guaraní en el Paraguay colonial: que contiene la creación de un lenguaje cristiano en las reducciones de los guaraníes en el Paraguay. CEPAG, Asunción.

MÉTRAUX, A. (1948). The Guaraní. En STEWARD, J. (ed.), Handbook of South american Indians, pp. 6894. Smithsonian Institution, Washington.

MONTENEGRO, P. (1945) [1710]. Materia Médica Misionera. Imprenta de la Biblioteca Nacional, Buenos Aires.

PERKINS DE PIACENTINO, A. M. (2007). Misiones Jesuíticas: drogas autóctonas americanas encontradas en la botica jesuítica de la ciudad de Santa María de Buenos Ayres. 38th International Congress for the History of Pharmacy, Sevilla. Disponible: https://idus.us.es/xmlui/bitstream/ handle/11441/39984/170.pdf; sequence $=1$. (Consulta: 14/01/18).

POLETTO, R. \& WELTER, S. C. (2011). A materia medica misionera do Ir. Pedro Montenegro (1710): Um estudo sobre as virtudes das plantas medicinais nativas americanas. Revista Historiador 4: 96-116.

POLETTO, R. (2014). Uma trajetória por escrito: Pedro Montenegro SJ. e sua Materia Medica Misionera. Tesis doctoral, Universidad do Valle do Rio dos Sinos, Brasil. 218 pp.

POU FERRARI, R. \& MAÑE GARZÓN, F. (2012). El Doctor Julepe. Vida y obra del Dr. Francisco Antonio Vidal (1827-1889). Plus Ultra, Montevideo.

RICCIARDI, A. I., CABALLERO, N. E. \& CHIFA, C. (1996). Identificación botánica de plantas descriptas en Materia Médica Misionera usadas en accidentes ofídicos. Rojasiana 3: 239-245.

ROSSO, C. N. \& SCARPA, G. F. (2012). Identificaciones botánicas de las plantas empleadas entre los mocovíes en la reducción San Javier durante el siglo XVIII a partir de la obra de Florian Paucke, S. J. En ARENAS, P. (ed.), Etnobotánica en zonas áridas y semiáridas del cono sur de Sudamérica, pp. 45-70. CEFYBO-CONICET, Buenos Aires.

ROSSO, C. N. (2013). La etnobotánica histórica: el caso mocoví en la reducción de San Javier en el siglo XVIII. Etnobiología 11: 54-65.

SCARPA, G. F. \& ANCONATANI, L. M. (2019). La "Materia Médica Misionera" atribuida al jesuita Pedro de Montenegro en 1710: Identificación, sistematización e interpretación de los usos medicinales de las plantas y sus implicancias para la etnobotánica actual. IHS. Antiguos Jesuitas en Iberoamérica 7: 27-46. https://doi.org/10.31057/2314.3908.v7.n1.24771

STAMPELLA, P. C., LAMBARÉ, D. A., HILGERT, N. I. \& POCHETTINO, M. L. (2013). What the iberic conquest bequeathed to us: the fruit trees introduced in argentine subtropic, their story and importance in present traditional medicine. Evidence-Based Complementary and Alternative Medicine 2013, ID 868394, 17 pages. https://doi.org/10.1155/2013/868394

STAMPELLA, P. C., ESPÓSITO, E. \& KELLER, H. A. (2019). Los frutales del nordeste argentino en la "Materia Médica Misionera" del jesuita Pedro Montenegro. Bonplandia 28: 99-116. https://doi.org/10.30972/bon.2823853

STAMPELLA, P. C., HILGERT, N. I. \& HERNÁNDEZBERMEJO, E. (2018). El papel de las misiones jesuíticas (s. XVII-XVIII) en la construcción de la selva misionera. Procesos de transferencia y resignificación. Actas del LVI Congreso Internacional de Americanistas, pp. 418-430.

SUSNIK, B. (1979-1980). Los aborígenes del Paraguay: Tomo II. Etnohistoria de los Guaraníes: época colonial. Escuela Técnica Salesiana, Asunción.

TANODI BRANKA, M. (2000). Documentos históricos, normas de transcripción y publicación. Cuadernos de Historia, Serie Ec. y Soc. $N^{\circ} 3$, Arch. y Ftes., CIFFyH-UNC, Córdoba. pp. 259-270.

THE PLANT LIST. (2013). A working list of all plant species. Disponible: http://www.theplantlist.org/. (Consulta 27/04/20).

TIBF Bs. As., Aimé Bonpland. Archive Inédites de Aimé Bonpland. Tomo 2 JOURNAL DE BOTANIQUE. Trabajos del Instituto de Botánica y Farmacología. Facultad de Ciencias Médicas de Buenos Aires $\mathrm{N}^{\mathrm{o}}$ 42. 1924. Folio 13 y 14, 2495-2502.

ZANOTTI, C. A., KELleR, H. A. \& ZULOAGA, F. O. (2020). Biodiversidad de la flora vascular de la provincia de Misiones, Región Paranaense, Argentina. Darwiniana, nueva serie 8(1). DOI: https://doi.org/10.14522/darwiniana.2020.81.878. 
